درجة رضا طالبات الدراسات العليا عن نظام بلاكبورد واستخدامه في تدريسهن الطارئ عن بعد في ضوء نموذج نجاح نظام المعلومات لديلون ومكلين

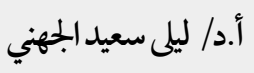


درجة رضا طالبات الدراسات العليا عن نظام بلاكبورد واستخدامه في تدريسهن الطارئ عن بعد في ضوء نموذج نجاح نظام المعلومات لديلون ومكلين

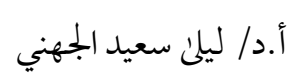

أستاذ تقنيات التعليم، قسم تقنيات التعليم - كلية التربية، جامعة طيبة، السعودية،

ljtechno@hotmail.co.uk

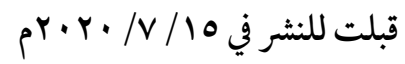

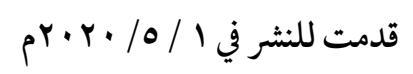

المستخلص: هدفت الدراسة إلى تقصي درجة رضا طالبات الدراسات العليا في تحصص تقنيات التعليم عن نظام بلاكبورد واستخدامه في تدريسهن الطارئ عن بعد في ضوء العوامل التي حددها نموذج

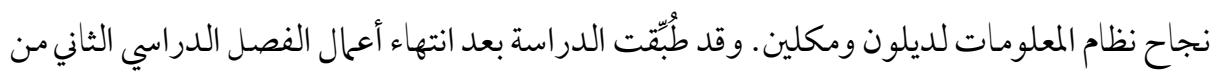
العام الدراسي (1441ه - 2020م) علن عينة تكونت من (30) طالبة؛ واسُتْخِدمَت استبانة من إعداد الباحثة استندت إلى نموذج نجاح نظام المعلومات لديلون ومكلين واشتملت علن ستة عو امل هي: (جودة النظام، جودة المعلومات، جودة الخدمة، رضا المستخدم، استخدام النظام، المنفعة الصافية). وقد أظهرت نتائج الدراسة أن جودة النظام، وجودة المعلومات، وجودة الخدمة، والمنفعة الصافية أثرت تأثيراً إيجابياً على رضا المستخدم، واستخدام النظام، كما أثر استخدام النظام على رضا المستخدم تأثيراً إيجابياً. الكلمات المفتاحية: رضا المستخدم، نظام بلاكبورد، الاستخدام، التدريس الطارئ عن بعد، نموذج نجاح نظام المعلومات لديلون ومكلين، نظم إدارة التعلم. 


\title{
Female Graduate Students' Degree of Satisfaction with Blackboard System and its Use in their Emergency Remote Teaching in Light of DeLone and McLean's Information System Success Model
}

\author{
Dr. Laila Saeed Aljohani \\ Professor of Educational Technology, Department of Educational Technology, \\ College of Education, Taibah University, Saudi Arabia, ljtechno@ @otmail.co.uk
}

\section{Received in 1st May 2020}

Accepted in 15th Jul 2020

\begin{abstract}
The study aimed to investigate the degree of satisfaction of graduate female students in Educational Technology specialization about the Blackboard system and its use in their emergency remote teaching in the light of DeLone and McLean's Information System Success Model. The study was applied after the end of the second semester of the academic year (1441 AH - 2020 AD) on a sample consisting of (30) female students. A questionnaire prepared by the researcher was used, based on DeLone and McLean's Information System Success Model, and it included six factors: (system quality, information quality, service quality, user satisfaction, system use, net benefits). The results of the study have shown that system quality, information quality, service quality, and net benefit positively affected the user's satisfaction and the use of the system, and that system use affected the user's satisfaction positively.
\end{abstract}

Key words: User Satisfaction, Blackboard System, Use, Emergency Remote Teaching, DeLone and McLean's Information System Success Model, Learning Management Systems. 


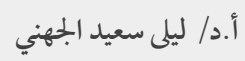

المجلد (3) العدد (4) 2020م

\section{Summary}

\section{Introduction}

During the first half of the year (2020), the Kingdom of Saudi Arabia witnessed - and the world witnessed with it - the outbreak of the new Corona virus (Covid-19), which belongs to a widespread viral group known to cause diseases ranging from common cold to the most severe diseases, such as Middle Eastern Respiratory Syndrome (MERS) and Severe Acute Respiratory Syndrome (SARS). Corona virus is a new strain of these viruses that have not been previously discovered in humans, and the common signs of infection with this virus include fever, coughing, and breathing difficulties. In more severe cases, the infection may be caused by pneumonia, severe acute respiratory syndrome, kidney failure and even death (WHO, 2020).

The World Health Organization has classified Covid-19 a global pandemic on March 11, 2020 (WHO, 2020). To slow down and prevent its spread, a number of countries followed strict measures, such as total closures, or restrictions on social distancing, while others preferred herd immunity. Efforts to stem the outbreak included working from homes, providing flexible working hours, or closing several institutions to avoid infection with the virus. These measures included the closure of school and university buildings and many other educational institutions. This situation forced all educational institutions to work and distance education (Bozkurt, \& Sharma, 2020).

International organizations, such as OECD and UNESCO, acknowledged the problem and undertook important initiatives to address it. In particular, UNESCO introduced the terms emergency and educational disruption for the effects of the crisis on education systems and called on governments and international organizations to take action to address the problem, using for the said solutions the term maintaining undisrupted learning, i.e. the continuity of learning in any way even outside the formal learning environments. This has obviously arisen as an option taking into account the situation worldwide and not only in developed countries, where more or less Internet was the media through which maintenance was possible (Karalis, 2020, 126).

This was accompanied by the term "emergency remote teaching" to distinguish between the emergency educational situation imposed by the precautionary measures 
to confront the new Corona virus, and the usual concept of online learning. Therefore (Hodges, Moore, Lockee, Trust, \& Bond, 2020) showed that in contrast to experiences that are planned from the beginning and designed to be online, emergency remote teaching is a temporary shift of instructional delivery to an alternate delivery mode due to crisis circumstances.

To implement emergency remote teaching, universities have resorted to using Learning Management System, which are programs designed to support and enhance the educational process, and manage, implement, and evaluate all learning activities (Al-Sadhan, 2015, 228-229).

As with any other Technology, the adoption of the Blackboard system in emergency remote teaching may involve a form of change that may be easy for some students; but complicated for others. Users of different abilities are expected to interact with it in a different way. Some may welcome it and feel satisfied with it, while others resist it (Noh, Mustafa, \& Ahmad, 2014, 145).

User satisfaction is one of the primary success criteria for any learning management system. Its evaluation and determinants are also an important practice for measuring the value and effectiveness of investing in that system. It is a user-performed evaluation for certain characteristics of the system, along a continuum of evaluation whether that evaluation is positive or negative, (Kassim, Jailani, Hairuddin \& Zamzuri, 2012, 412).

There are a number of models that have been employed to investigate the success of any learning management system and user satisfaction with it, perhaps the most common and widely used one is of DLone and McLean's Information System Success Model. William H. DeLone and Ephraim R. McLean have reviewed the published studies during the period (1981-1990 AD), and based on that review, they built their information system success model. Then they updated their model in a study published in (2003) by adding variables: intent to use, service quality, and merging individual and organizational impact into one structure called net benefit. The model provides a valuable framework for understanding the multiple factors influencing the success of any information system that includes system quality, information quality, 
service quality, user satisfaction, system use, net benefits (DeLone, \& McLean, 2016, 6-11).

A number of studies have sought to implement DLone and McLean's Information System Success Model in investigating the success of a number of learning management systems, whether they are open source systems such as: Moodle, or closed source such as: Blackboard, among them are (Liaw, 2007; Ramayah \&Lee, 2012; Kusumawati, Pribadi \& Astuti, 2013; Tahar, Mokhtar, Jaafar, Zamani, Sukiman, \& Ismail, 2013; Eom, 2014; de Souza Meirelles, Filenga \& Brugnolo Filho, 2014; Yosep, 2015; Dreheeb, Basir \& Fabil, 2016; Ghazal, Aldowah \& Umar, 2017; Yakubu \& Dasuki, 2018; Ohliati \& Abbas, 2019; Freeze, Alshare, Lane \& Wen, 2019; Kurt, 2019; Salam \& Farooq, 2020).

\section{Study hypotheses}

The study is based on the DeLone, \& McLean's updated information success model, as a regulatory framework for it; due to its usefulness, comprehensiveness, conciseness and popularity (DeLone, \& McLean, 2016, 5). Based on the specific model, the study sought to verify the following hypotheses:

- H1a: System quality has a positive impact on user satisfaction.

- H1b: System quality has a positive impact on system use.

- H2a: Information quality has a positive impact on user satisfaction.

- H2b: Information quality has a positive impact on system use.

- H3a: Service quality has a positive impact on user satisfaction.

- H3b: Service quality has a positive impact on system use.

- H4: System use has a positive impact on user satisfaction.

- H5: User satisfaction has a positive impact on system use.

- H6: System use has a positive impact on net benefit.

- H7: User satisfaction has a positive impact on net benefit.

- H8: Net benefit has a positive impact on system use.

- $\quad$ H8: Net benefit has a positive impact on user satisfaction.

\section{Study Objective}


The study aimed to investigate the degree of satisfaction of graduate female students in Educational Technology specialization about the Blackboard system and its use in their emergency remote teaching in the light of DeLone and McLean's Information System Success Model.

\section{Study Approach}

The study followed the descriptive approach that seeks to describe a phenomenon or problem, and to quantify it quantitatively by collecting data and codified information about it, then classifying, analyzing, and interpreting that information; to come up with a deeper understanding of the phenomenon or problem under consideration (Shields \& Rangarajan, 2013).

\section{Study Population and Sample}

The study population consists of (39) female postgraduate students who were registered with a master's degree in Educational Technology specialization, in the College of Education, Taibah University in Medina, during the second semester of the academic year (1441AH - 2020AD), one of them was excluded, given that she was dropped the semester. A link to the questionnaire of the study has been sent to all female students (38) who were continuing their studies, after completing its preparation through Google Forms and arbitration it, and (30) students of them responded forming the study sample.

\section{Study Tool}

The study used a questionnaire based on DeLone and McLean's Information System Success Model. It was built after reviewing previous studies related to the subject of the study such as the study of Yakubu and Dasuki (2018), the study of Freeze, Alshare, Lane \& Wen, 2019, and the study of Salam and Farooq (2020). It consisted in its primary form of (30) terms that fall under (6) factors: system quality, information quality, service quality, user satisfaction, system use, and net benefit; (5) sentences under each factor. It is listed according to Likert pentatonic scale as follows: (strongly agree - approve - somewhat agree - disagree - strongly disagree).

Content validity of the questionnaire was calculated by presenting it to a number of arbitrators in Educational Technology and Curricula and Teaching Methods 
specializations, then it was modified based on their observations by reformulating some of the sentences. Validity was also calculated by calculating the internal consistency to determine Pearson correlation coefficients to measure the relationship between the questionnaire factors of the degree of satisfaction with Blackboard system and its use in emergency remote teaching, with the total degree of the questionnaire, the factors were significant correlation coefficients at (0.01) level.

As for the reliability of the questionnaire, it was calculated by determining Cronbach's Alpha factor. The factors ranged between: $(0.92-0.95)$, and the total reliability of the questionnaire reached $(0.97)$, which are indicated the validity of the questionnaire.

\section{Study Results}

The results of the study have shown that system quality, information quality, service quality, and net benefit positively affected the user's satisfaction and the use of the system, and that system use affected the user's satisfaction positively. 
شهدت المملكة العربية السعودية - وشهد العالم معها - خلال النصف الأول من عام (2020م) تفشي فيروس كورونا المستجد (كوفيد - 19/ Covid-19) الذي ينتمي إلى فصيلة فيروسات واسعة الانتشار عُرفت بتسبها بأمراض تتراوح بين نزلات البرد الشائعة إلى الأمراض الأشد حدةً، مثل فئل

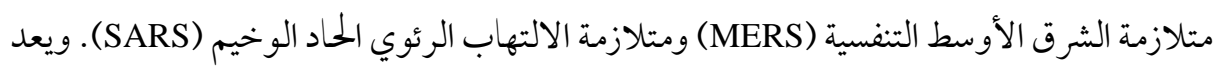
فيروس كورونا المستجد سلالة جديدة من تلك الفيروسات لم يسبق اكتشافها لدئ البشر. وتشمل علامات العدوئ الشائعة بهذا الفيروس: الحمىن والسعال وصعوبات التنفس. وفي الأحوال الأشد

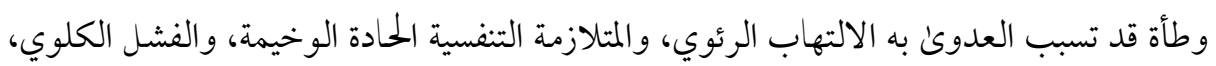
وحتى الوفاة (منظمة الصحة العالمية، 2020م).

وقد صنفت منظمة الصحة العالمية فيروس كورونا المستجد جائحة (Pandemic) عالمية في الحادي عشر من مارس (WHO, 2020) (2020). ولإبطاء انتشاره ومنعه، اتبع عدد من الدول إجراءات صارمة، مثل الإغلاق الكامل، أو فرض قيو د التباعد الاجتماعي، في حين فضلت دول أخرىن

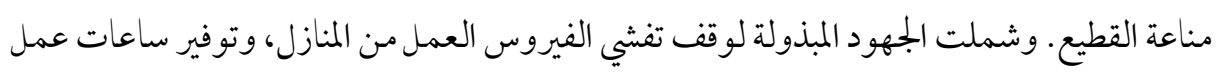
مرنة، أو إغلاق العديد من المؤسسات تجنباً للعدوئ بالفيروس. وقد شملت هذه الإجراءات إغلاق مباني المدارس والجامعات والعديد من المؤسسات التعليمية الأخرىن. وأجبر هذا الوضع جميع المؤسسات التعليمية علئ العمل و التعليم عن بعد (Bozkurt, \& Sharma, 2020). ولم يكن التعليم في المملكة العربية السعودية بمنأنى عن التأثر بأزمة فيروس كورونا المستجد كغيره من نظم التعليم الأخرى حول العالم، إذ اتخذت وزارة التعليم قراراً بتعليق الدراسة مؤقتاً في جميع

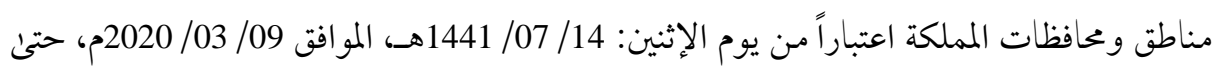
إشعار آخر. وشمل القرار مدارس ومؤسسات التعليم العام والأهلي والجحامعي والمؤسسة العامة للتدريب التقني والمهني الحكومية والأهلية. وقد وجهت الوزارة بتفعيل المدارس الافتراضية والتعليم 
عن بُعد خلال فترة تعليق الدراسة، لضمان استمرار العملية التعليمية بفاعلية وجودة (وكالة الأنباء السعودية، 2020).

وانطلاقاً من تأثير هذ الوضع الطارئ غير المسبوق، اعترفت المنظات الدولية، مثل منظمة

التعاون والتمية في الميدان الاقتصادي ( Organization for Economic Co-operation and (Development $\boldsymbol{O E C D}$

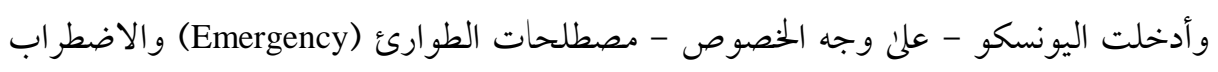

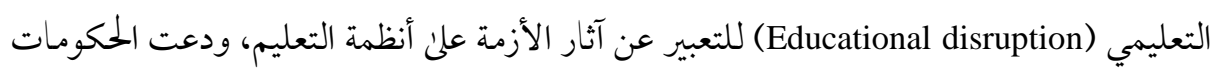

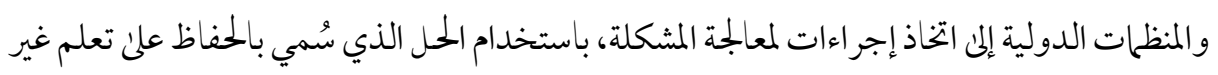

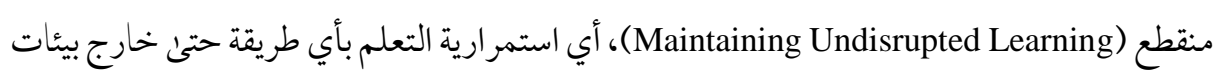

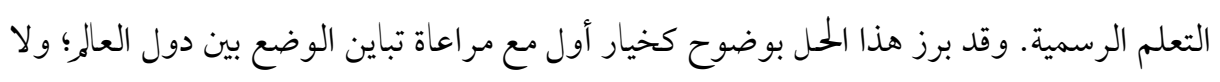

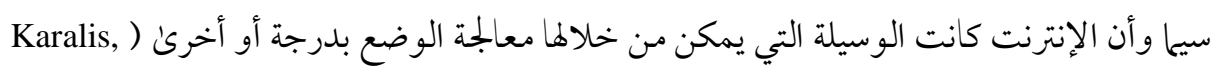
. $(2020,126$

وقد رافق ما سبق ظهور مصطلح التدريس الطارئ عن بعد ( Emergency Remote

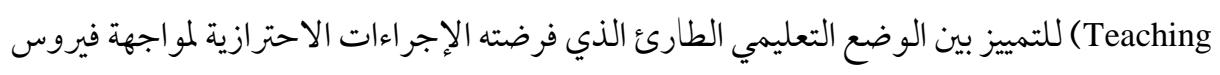

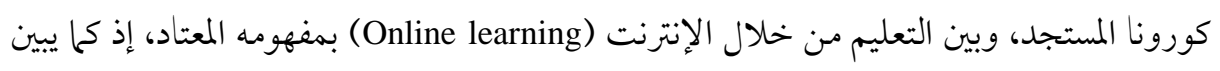

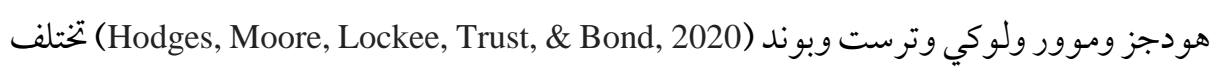
خبرات التعليم من خلال الإنترنت المخطُّط لها جيداً اختلافاً جذرياً عن الدروس المقدمة من خلال

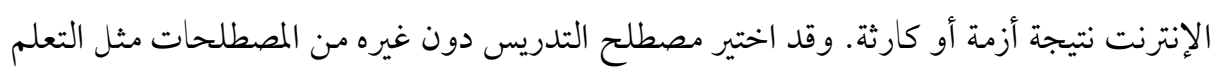

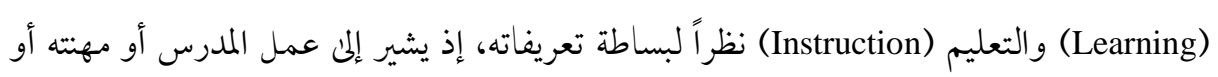

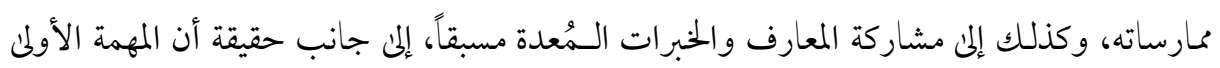

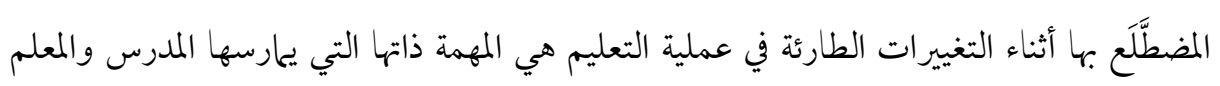

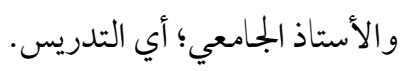


وخلافاً للخبرات المصمَّمة والمخطَّط لتقديمها من خلال الإنترنت منذ البداية، يعد التدريس الطارئ عن بعد تحو لاً مؤقتاً من التعليم وجهاً لوجه إلى وضع بديل نتيجة الظروف التي فرضَتها أزمة فيروس كورونا المستجد؛ ففي حين ينطوي علن اللجوء إلى حلول التعليم عن بعد بالكامل، فهو يتضمن إشارة مبطنة إلى أن الأمور ستعود إلى النموذج المعتاد عند انتهاء الأزمة أو الطوارئ هذه، إذ لا يكمن الهدف الأساسي منه في إعادة بناء نظام تعليمي قوي، بل في توفير وصول مؤقت إلى التعليم، ودعمه

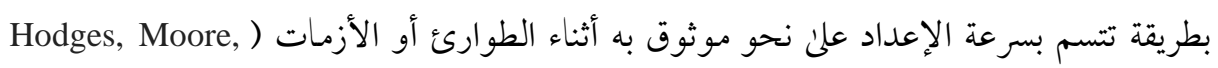
.(Lockee, Trust, \& Bond, 2020 وفي هذا الصدد، يعد استخدام التعريف الصحيح أمراً مههاً؛ لأن الاندفاع نحو التدريس هال الطارئ عن بُعد، أو تسميته بالتعليم عن بعد (Distance learning) أو التعلم من خلال الإنترنت،

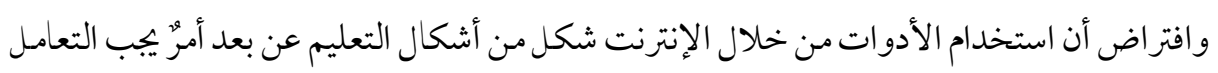
معه بحذر؛ لأن تصميم أنظمة التعلم وفقاً لافتراضات الخاطئة، وتأطيرها حول تعريفات خاطئة سيجعلها أكثر عرضة للأخطاء. كما أن الأزمة ستنتهي وتعود الأمور إلى طبيعتها، وقد يكون ما سيتذكره الناس منها أمثلة سيئة عن التعليم عن بعد تحتنفي معها فجأة أعوام من الجها المبذول لإثبات فاعليته. لذلك، يقع علن عاتق التربويين مسؤولية التحدث بصدق، وتوفير حلول عمل و استخدام المصطلحات بعناية وعن قصد (Bozkurt, \& Sharma, 2020). ولتنفيذ التدريس الطارئ عن بُعد لجأت الجامعات إلى استخدام نظم إدارة التعلم ( Learning (Management System LMS أنشطة التعلم، وتنفيذها، وتقييمها (السدحان، 2015، 228-229). وكان من أكثر تلك الأنظمة استخداماً نظام بلاكبورد (Blackboard)، وهو نظام مغلق المصدر تقدمه شر كة بلاكبورد التي تعد أكبر شركة تقنيات وخدمات تعليمية في العالم، وتخدم ما يقرب من (100) مليون مستخدم ينتشرون في كل أنحاء العالم. و كانت بلاكبورد قد أنشئت من قبل مجموعة من الأصدقاء الذين استشرفو امعاً مستقبل التعلم. فمع ظهور الإنترنت، رأن الشابان مايكل شاسن (Michael Chasen) وماثيو بيتينسكي 
إمكانات التقنية في دعم التدريس والتعلم في التعليم العالي. وبعد تأسيس (Matthew Pittinsky) شركتها في عام (1997م) ببدايات متو اضعة، انضم إليها دانيال كاين (Daniel Cane)، وستيفن غليفوس (Stephen Gilfus)، اللذين شاركها رؤيتها لمستقبل التعلم الرقمي، و افتتحا عملها الريادي ببناء نظام إدارة مقرر (Course Management System) بينما كانا لا يزالان طالبين في مرحلة البكالوريوس في جامعة كورنيل (Cornell University)، ودبجاه مع شركة بلاكبورد، ثم أعلن الأصدقاء عن إنشاء شركتهم في عام (Blackboard, 2020a) (2004م). ومثل أي تقنية أخرى قد ينطوي اعتماد استخدام نظام بلاكبورد في التدريس الطارئ عن بعد علن شكلٍ من أشكال التغيير الذي قد يكون سهلاً عند بعض الطلاب؛ ومعقداً عند آخرين. ويتوقع أن يتفاعل معه المستخدمون - علن اختلاف قدراتهم - بطريقة متباينة. إذ قد يرحب بعضهم به ويشعر بالرضا عن استخدامه، في حين يقاومه آخرون (Noh, Mustafa, \& Ahmad, 2014, 145). ويُشار هنا إلى أن الخطوة الأساسية الأولى لتحقيق نجاح أي نظام إدارة تعلم - بها في ذلك نظام بلاكبورد تتمثل في القبول المبدئي من المستخدم النهائي والرضا عن استخدامه، فيا يكمن النجاح الحقيقي في استدامة استخدام ذلك النظام (Dreheeb, Basir \& Fabil, 2016, 13). ويعد رضا المستخدم أحد معايير النجاح الأساسية لأي نظام إدارة تعلم. كما يعد تقييمه ومحدداته ممارسة مهمة لقياس قيمة وفعالية الاستثمار في ذلك النظام. وهو تقييم يقوم به المستخدم، علن

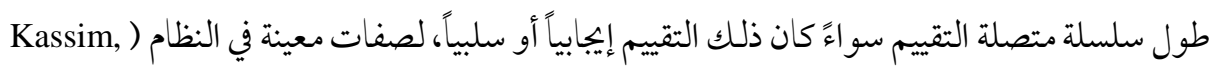
(Jailani, Hairuddin \& Zamzuri, 2012, 412 رضا المستخدم يعد الوسيط المركزي لسلوك ما بعد التعلم الذي يربط المعتقدات التي تسبق استخدام النظام بكل من: الهيكل المعرفي المتكون بعد الاستخدام، واتصالات الطلاب، وسلوك إعادة الاستخدام. ويتفق معظم الباحثين في السلوك علن أن الرضا يؤثر علن نية الاستخدام في المستقبل، كما أنه يؤثر علن سلوك الشكوى لدى الطلاب، ومن المتوقع أن يكون لدى الطلاب ذوي مستويات الرضا العالية مستويات أعلى من نية إعادة الاستخدام ومستوئ أقل من الشكاوئ. 
وهناك عدد من النماذج التي وظّفت في تقصي مدىن نجاح أي نظام إدارة تعلم ورضا المستخدم

عند، لعل من أكثرها شيو عاً واستخداماً نموذج نجاح نظام المعلومات لديلون ومكلين ) William H. (McLean's Information System Success Model (DeLone وإفرايم آر. مكلين (Ephraim R. McLean) الدراسات المنشورة خلال الفترة (19811990م)، وبناءً علن تلك المراجعة بنيا نموذج نجاح نظام المعلومات استناداً إلى نظرية شانون وويفر عن الاتصال؛ فقد عرّف شانون وويفر المستوكئ التقني لنظام الاتصال بأنه (Shannon and Weaver) دقة وكفاءة النظام الذي ينتج المعلومات؛ والمستوى الدلالي بنجاح النظام في نقل المعنى المقصود؛ أمـا مستوى الفاعلية فعرفه بتأثير المعلومات على المتلقي. كما استندا في بناء نموذجها إلى تعريف ماسون

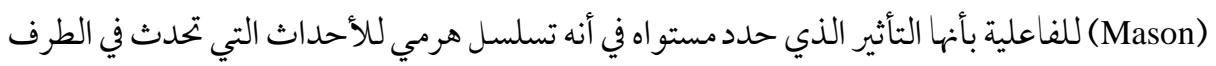
المستقبِل لنظام معلومات والتي قد تُستخدم لتحديد المداخل المختلفة التي يمكن استخدامها لقياس المخرجات عندمستوئ التأثير . وقد حدد ديلون ومكلين ستة أبعاد لنموذج قياس نجاح نظم المعلومات في صورته الأولن هي: جودة النظام (المستوى الفني)؛ جودة المعلومات (المستوى الدلالي)؛ DeLone, \& McLean, ) والاستخدام، ورضا المستخدم، والأثر الفردي وأثر المنظمة (مستوى التأثير) (2016, 5-6)، كما يظهر في الشكل الآتي.

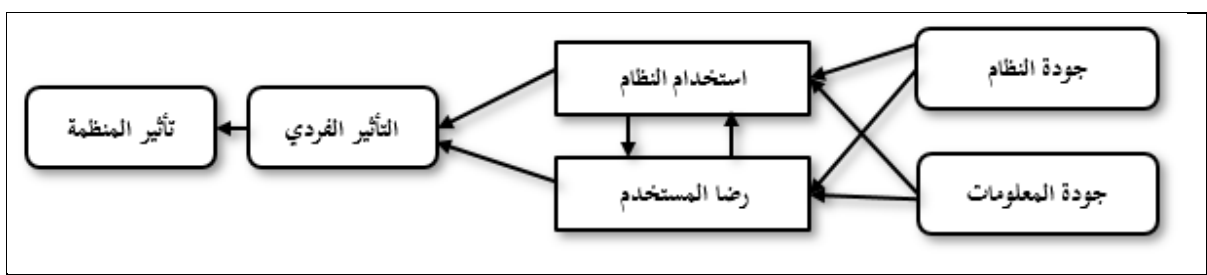

شكل (1): نموذج نجاح نظام المعلومات لديلون ومكلين في صورته الأولن : المعلى

المصدر: (DeLone, \& McLean, 2016, 6)

وبعد نشر النموذج مباشرة، اقترح عدد من الباحثين بعض التعديلات عليه، واستجابة لذذه الاقتراحات، وبعد مراجعة الدراسات التجريبية التي أجريت خلال الأعوام التي تلت نشر النموذج في صورته الأولن؛ حدّث ديلون ومكلين نموذجها في دراسة نُشرت في عام (2003م)، وذلك بإضافة 
متغيرات: نية الاستخدام، وجودة الخدمة، ودمج التأثير الفردي وتأثير المنظمة في بنية واحدة سميت بالمنفعة الصافية، (DeLone, \& McLean, 2016, 6-8) كما يظهر في الشكل التالي.

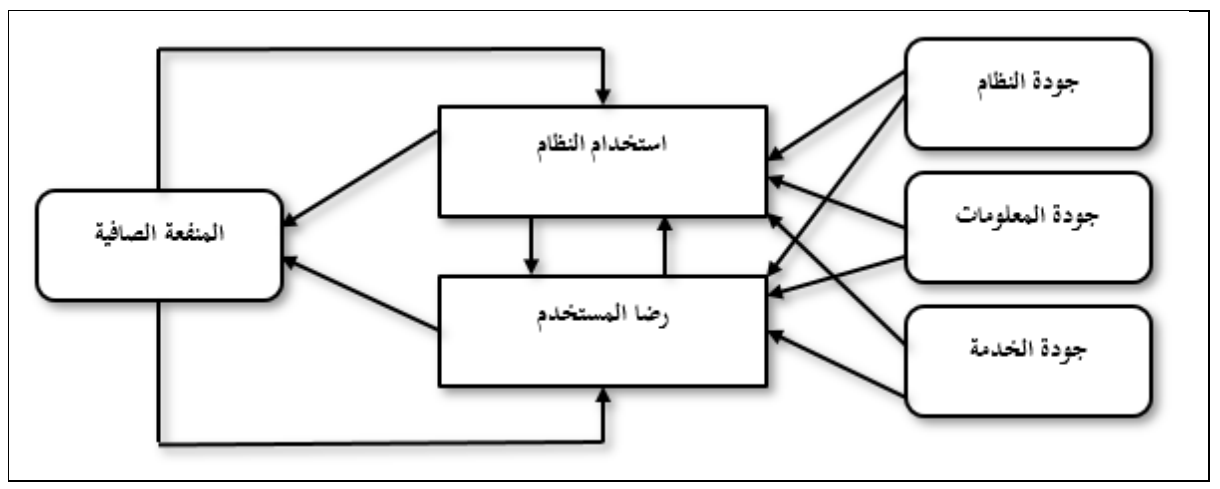

شكل (2): نموذج نجاح نظام المعلومات لديلون ومكلين المحدث

المصدر: (DeLone, \& McLean, 2016, 9)

ويوفر نموذج ديلون ومكلين إطار عمل قيم لفهم العوامل المتعددة المؤثرة على نجاح أي نظام

معلومات التي تشمل (DeLone, \& McLean, 2016, 9-11):

- - جودة النظام (System quality): أي الخصائص المرغوب في توافرها في نظام المعلومات،

مثل سهولة الاستخدام، والمرونة، والدقة، وسهولة تعلمه، بالإضافة إلى التعقيد والوقت

$$
\text { الذي يستغرقه النظام في الاستجابة للمستخدم. }
$$

- - جودة المعلومات (Information quality): أي الخصائص المرغوب في توافرها في خخرجات النظام؛ أي تقارير الإدارة وصفحات الإنترنت، مثل الملاءمة، قابلية الفهم، الدقة، الإيجاز،

$$
\text { الاكتمال، حسن التوقيت، وسهولة الاستخدام. }
$$

- - جودة الخدمة (Service quality): أي جودة الدعم الذي يتلقاه مستخدمو النظام من موظفي أنظمة المعلومات وتقنية المعلومات في المنظمة، مثل الاستجابة والدقة والكفاءة الفنية

$$
\text { و التعاطف من قبل موظفي تقنية المعلومات. }
$$

- رضا المستخدم (User satisfaction): أي مستوكن رضا المستخدمين عن التقارير ومواقع

$$
\text { الويب وخدمات الدعم التي يقدمها النظام. }
$$


- - الاستخدام (Use): أي الدرجة والطريقة التي يستخدم بها المستخدمون قدرات النظام

$$
\text { المعلومات، مثل مقدار الاستخدام، وتكراره، وطبيعته، وملاعمته، و الغرض منه. }
$$

- - - منفعة الصافية (Net benefits): أي مدى' مساهمة نظام المعلومات، أو عدم مساهمته في نجاح

$$
\text { الأفر اد والمجموعات والمنظات، من خلال تحسين عملية صنع القرار، وتحسين الإنتاجية. }
$$

ويعد فهم نجاح نظم إدارة التعلم مجال عناية مستمرة ليس للباحثين فحسب، بل كذلك

للممارسين وأصحاب المصلحة في المؤسسات التي تستخدم تلك النظم، إذ يساعد هذا الفهم في إبراز قيمتها، ويمكن أن يكون أساساً تبنى عليه القرارات اللاحقة المتعلقة بها (Ojo, 2017, 61). وتكمن أهمية استقصاء نجاح هذه النظم في بجال التعليم في أن استخدامها يُبنى - في كثير من الأحيان - علن افتراض بأن جميع المستخدمين سيستخدمونها ويتعلمون منها بالطريقة نفسها، وهو نهج شائع عند تصميم نظم إدارة التعلم، وتكمن مشكلة هذا النهج في تجاهله لقضايا الفروق الفردية بين المستخدمين رغم أهميتها (Zamzuri, Shahrom, Kasim, Nasir \& Mamat, 2012, 428). إضافة إلى ما سبق، فإن مبادرات التدريس الطارئ عن بعد وجميع إجراءاتها لم تكن مجربة من قبل، وفي بعض الأحوال، له تُطبّق بدرجة ثابتة من خلال المؤسسات التعليمية (Vlachopoulos, 2020, 17). وفي الواقع، فإن ما يُدرّسُ في هذه الأوقات يمكن أن يكون له أهمية ثانوية، فلن يتذكر الطلاب المحتوى التعليمي الذي

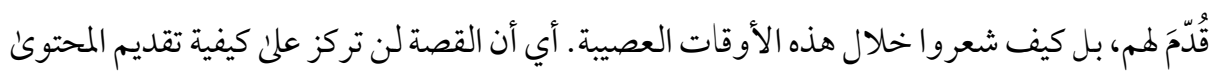

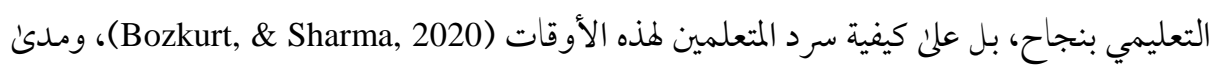
Hodges, Moore, Lockee, Trust, رضاهم عنها. وكما يشير هودجز وموور ولوكي وترست وبوند

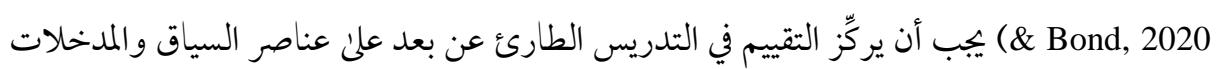
التي تندرج نظم إدارة التعلم تحتها ويجب بناءً عليه دراسة مدى' نجاحها من وجهة نظر مستخدميها. وقد سعى عدد من الدراسات إلى تطبيق نموذج نجاح المعلومات لديلون ومكلين في تقصي نجاح عددمن نظم إدارة التعلم، سواءً كانت نظلاً مفتوحة المصدر مثل: موودل، أو مغلقة المصدر مثل: بلاكبورد، إذ أجرىئ لياو (Liaw, 2007) دراسة سعت إلى استقصاء رضا المستخدم ونيته السلو كية نحو

\section{http://dx.doi.org/10.29009/ijres.3.4.6}


استخدام نظام بلاكبورد. طبقت الدراسة استبانة دُرّت وفق مقياس ليكرت (Likert) السباعي، وتضمنت (8) عوامل من بينها: جودة النظام، ونية الاستخدام، وقد تكونت عينتها من (424) طالباً وطالبة من يدرسون باستخدام نظام بلاكبورد في إحدى الجامعات في تايوان، وقد أظهرت النتائج أن

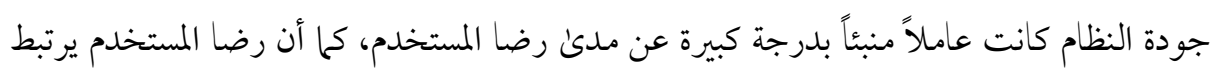
ارتباطاً إيجابياً بنية الاستخدام.

وأجرى رامايه ولي (Ramayah \& lee, 2012) دراسة هدفت إلى قياس رضا المستخدم عن نظام إدارة التعلم واستخدامه في إحدى الجامعات الحكومية في ماليزيا. طبقت الدراسة استبانة تضمنت (5) عو امل هي: جودة المعلومات، وجودة النظام، وجودة الخدمة، ورضا المستخدم، ونية الاستخدام. وتكونت عينتها من (250) طالباً وطالبة يدرسون في مر حلة البكالوريوس في جامعة حكومية ماليزية.

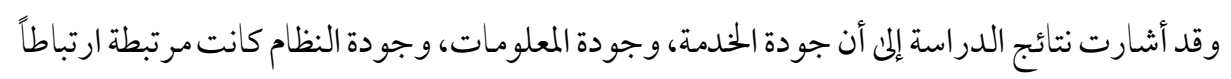
إيجابياً برضا المستخدم، كما أن رضا المستخدم، وجودة النظام، وجودة الخدمة ترتبط ارتباطاً إيجابياً بنية الاستمرار في استخدام النظام.

كما نفذ كوسوماواتي وبريبادي وأستوتي (Kusumawati, Pribadi \& Astuti, 2013) دراسة هدفت إلى تحليل تأثير جودة نظام التعليم الإلكتروني المستخدم في أحد المعاهد التقنية في أندونيسيا، علن رضا المستخدم. طبقت الدراسة استبانة تضمنت (5) عوامل من بينها: جودة الخدمة، وجودة المعلومات، وجودة النظام، ورضا المستخدم، وتكونت عينتها من (88) طالباً وطالبة في مرحلة البكالوريوس في تخصص نظم المعلومات بمعهد تكنولوجي سيبالوه نوبمبر ( Institut Teknologi (Sepuluh Nopember النظام تؤثر تأثيرًا إيجابياً على رضا المستخدم.

Tahar, Mokhtar, Jaafar, ) وطبق طاهر وختار وجعفر وزماني وسوكيان وإسماعيل (Zamani, Sukiman, \& Ismail, 2013 رضا المستخدم في التعليم المدمج استناداً إلى نموذج نجاح نظام المعلومات لديلون ومكلين. طبقت 
الدراسة استبانة دُرّجت وفق مقياس ليكرت الخحاسي، واشتملت علئ (5) عو امل هي: جودة الخدمة، وجودة النظام، وجودة المعلومات، ورضا المستخدم، ونية الاستخدام، وتكونت عينتها من (75) طالباً وطالبة ممن يدرسون مقرر أصول الإدارة في جامعة تكنولوجي مارا (Teknologi MARA) في أندونيسيا بنمط التعليم المدمج. وقد أشارت النتائج إلى أن جودة الخدمة، وجودة النظام، وجودة المعلومات تؤثر تأثيراً إيجابياً على رضا المستخدم. وأجرىن إوم (Eom, 2014) در اسة سعت إلى تطبيق نموذج لقياس رضا المتعلمين عن استخدام نظام إدارة التعلم موودل (Moodle) يتضمن (5) عو امـل من بينها: جودة المعلومات. طبقت الدراسة استبانة دُرِّجت وفق مقياس ليكرت السباعي، وتكونت عينتها من (633) طالباً من طلاب مرحلتي

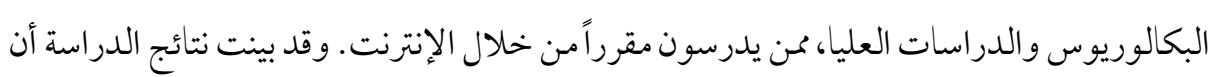
هناك علاقة إيجابية قوية بين جودة المعلومات ورضا المستخدم عن نظام موودل. ونفذ دي سوزا ميريليس وفيلنغا وبرغنولو فيلهو ( de Souza Meirelles, Filenga (Brugnolo Filho, 2014 الحلدمة ورضا المستخدم واستخدام نظام إدارة التعلم موودل في بيئات التعلم الافتراضية باستخدام نموذج نجاح نظام التعلم الإلكتروني الذي كيّيف من نموذج نجاح نظام المعلومات لديلون ومكلين. طبقت الدراسة استبانة تضمنت (6) عوامل هي: جودة النظام، وجودة المعلومات، وجودة الخدمة، ورضا المستخدم، والاستخدام، وتكونت عينتها من (291) طالباً وطالبة يتتمون إلى معاهد حكومية وخاصة في (5) مناطق من البرازيل، ويدرسون برنامجاً من خلال الإنترنت بعنوان: فنيات المقابلة و الاختيار . وقد أشارت النتائج إلى أن جودة النظام وجودة المعلومات وجودة الخدمة تؤثر تأثيراً إيجابياً على رضا المستخدم وعلن استخدام النظام. و أجرىن يوسب (Yosep, 2015) دراسة هدفت إلى تقييم قدرة نظام إدارة التعلم الإلكتروني، المطبق في جامعة بينا نوسانتارا التي تعد أول وأهم مؤسسة للتعليم عن بعد في أندونيسيا، على تعزيز

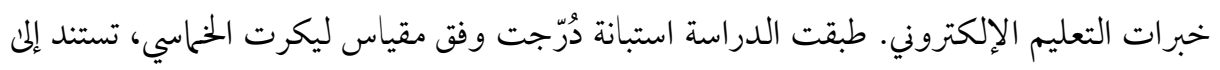


نموذج نجاح نظام المعلومات لديلون ومكلين، وتضمنت (5) عو امل هي: جودة المعلومات، وجودة النظام، وجودة الخدمة، ورضا المستخدم، والمنفعة الصافية، وتكونت عينتها من (75) طالباً يدرسون عن بعد. وقد بينت النتائج أن لجودة المعلومات وجودة النظام وجودة الخدمة تأثيراً إيجابياً على رضا المستخدم، كما أن رضا المستخدم يتأثر تأثيراً إيجابياً قوياً بالمنفعة الصافية. كحا نفذ دريهيب وبصير وفابيل (Dreheeb, Basir \& Fabil, 2016) دراسة هدفت إلى استقصاء أثر جودة النظام على رضا المستخدم عن نظام إدارة التعليم الإلكتروني واستمراره في استخدامه. طبقت الدراسة استبانة شملت (6) عو امل من ضمنها: جودة النظام، ورضا المستخدم، واستمرار الاستخدام، وتكونت عينتها من (408) طلاب وطالبات يدرسون في مر احل مختلفة (بكالوريوس، دبلوم، ماجستير، دكتوراه)، وينتمون إلى عدد من الجامعات الحكومية الماليزية. وقد أوضحت نتائج الدراسة أن جودة

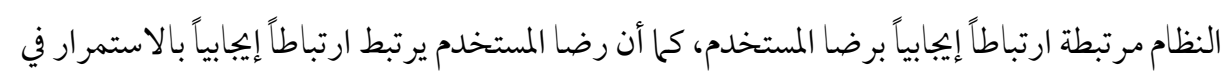
استخدام النظام. وأجرىن غزال والدواح وعمر (Ghazal, Aldowah \& Umar, 2017) دراسة هدفت إلى استكشاف العو امل الحاسمة التي تؤثر علن قبول الطلبة لأنظمة إدارة التعلم ورضاهم عنها في بيئات

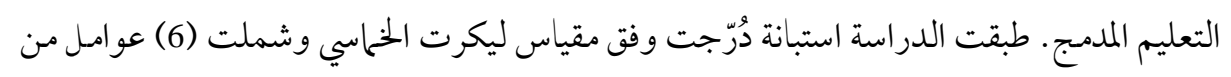
ضمنها: جودة النظام، وجودة المعلومات، وجودة الخدمة، ورضا المستخدم، في كلية التعليم المفتوح

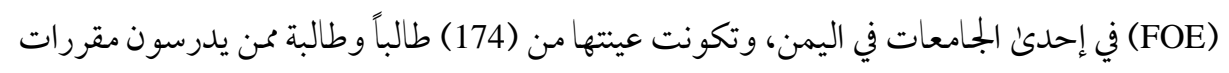

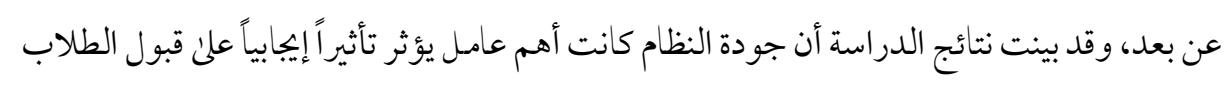
لأنظمة إدارة التعلم ورضاهم عنها، كما أشارت إلى أن لجودة المعلومات كذلك تأثير إيجابي كبير علن رضا المستخدم.

وطبّق ياكوبو وداسوكي (Yakubu \& Dasuki, 2018) دراسة سعت إلى تقييم نجاح نظام إدارة التعلم كانفاس (Canvas) في إحدى الجحامعات الخاصة في نيجيريا، من خلال تطبيق نموذج نجاح نظم المعلومات لديلون ومكلين. طبقت الدراسة استبانة درّجت وفق مقياس ليكرت الخحاسي، 
وتضمنت (6) عوامل هي: جودة النظام، وجودة المعلومات، وجودة الخدمة، ورضا المستخدم، والنية السلو كية، والاستخدام الفعلي، وتكونت عينتها من (366) طالباً وطالبة. وقد بينت نتائج الدراسة أن كلاً من جودة النظام وجودة المعلومات لا تؤثران على رضا المستخدم، في حين تؤثر جودة الخدمة تأثيراً إيجابياً على رضا المستخدم. ونفذ أوهلياتي وعباس (Ohliati \& Abbas, 2019) دراسة سعت إلى استقصاء العو امل المؤثرة علنى رضا المستخدم عن نظام إدارة التعلم في إحدىن جامعات التعليم عن بعد الخاصة. طبقت الدراسة استبانة دُرّجت وفق مقياس ليكرت الخحاسي، وتضمنت (6) عو امل من بينها: جودة المعلومات، وجودة النظام، وجودة الخدمة، وتكونت عينتها من (100) طالب ممن يدرسون في مرحلة الماجستير في تخصصي: تقنية المعلومات، ونظم المعلومات الإدارية. وقد أظهرت النتائج أن لجودة المعلومات، وجودة الخحمة

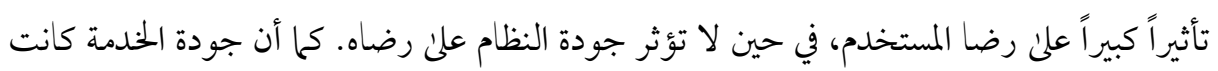
العامل الأكثر شيوعاً الذي يؤثر علن رضا المستخدم عن نظام إدارة التعلم. كما أجرى فريز والشاعر ولين وون (Freeze, Alshare, Lane \& Wen, 2019) دراسة سعت إلى قياس نجاح نظام إدارة التعليم الإلكتروني من خلال تطبيق نموذج نجاح نظام المعلومات من وجهة نظر الطلبة. طبقت الدراسة استبانة دُرّجت وفق مقياس ليكرت السباعي، واشتملت علئ (5) عو امل من ضمنها: جودة النظام، وجودة المعلومات، واستخدام النظام، ورضا المستخدم، وتكونت عينتهامن (674) طالباً وطالبة ممن يدرسون مقرراً واحداً علن الأقل عن بعد، ويتتمون إلى عدة تخصصات في مرحلتي البكالوريوس والدراسات العليا في إحدى جامعات الغرب الأوسط في أمريكا. وكشفت النتائج عن أن جودة النظام وجودة المعلومات كان لهما تأثير إيبابي كبير علن رضا المستخدم واستخدام النظام.

وطبّق كورت (Kurt, 2019) دراسة هدفت إلى فحص نظام إدارة التعلم موودل من وجهة نظر الطلاب من خلال استخدام نموذج نجاح نظم المعلومات. طبقت الدراسة استبانة دُرّت وفق مقياس ليكرت الخحاسي، واشتملت على (4) عوامل هي: جودة النظام، وجودة المعلومات، واستخدام النظام، 
ورضا المستخدم. وتكونت عينتها من (144) طالباً وطالبة يستخدمون نظام موودل في جامعة حكومية في روما، إيطاليا. خضعت البيانات لتحليل نمذجة مسار PLS عبر Smart PLS 3.0. وبينت النتائج أنه في حين أن جودة النظام ها تأثير كبير علن كل من استخدام النظام ورضا المستخدم، فإن جودة المعلومات لها تأثير كبير علن رضا المستخدم فحسب. كما يؤثر كل من رضا المستخدم واستخدام النظام تأثيراً إيجابياً على نجاح النظام. ونفذ سلام وفاروق (Salam \& Farooq, 2020) دراسة هدفت إلى استكشاف تأثير جودة المخالطة الاجتماعية علن استخدام نظام معلومات التعلم التعاوني علن شبكة الإنترنت ورضا المستخدم

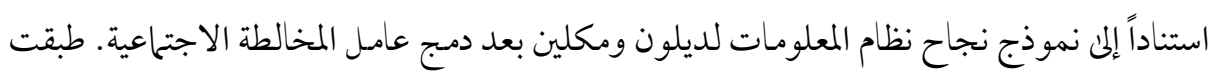
الدراسة استبانة دُرّجت وفق مقياس ليكرت السباعي، وتضمنت (7) عوامل منها: جودة النظام، وجودة المعلومات، وجودة الخدمة، ورضا المستخدم، واستخدام النظام، والمنفعة الصافية، وتكونت عينتها من (80) طالباً يدرسون أحد المقررات عن بعد في مرحلة البكالوريوس في إحدى الجامعات الماليزية. وقد أظهرت النتائج أن جودة النظام وجودة الخدمة تؤثران على رضا المستخدم؛ في حين لا تؤثر جودة المعلومات على رضا المستخدم وعلئ استخدام النظام. كما لا تؤثر جودة النظام وجودة الخدمة علن استخدام النظام، في حين يؤثر رضا المستخدم واستخدام النظام على المنفعة الصافية ويعدان مؤشراً قوياً عليها.

ويظهر من خلال الدراسات السابقة اتفاق معظمها علن أن جودة النظام، وجودة المعلومات،

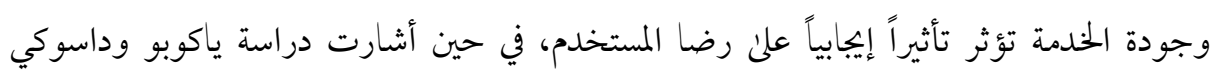
(Yakubu \& Dasuki, 2018) النظام لا تؤثر على رضا المستخدم، وانفردت دراسة ياكوبو وداسوكي (Yakubu \& Dasuki, 2018)

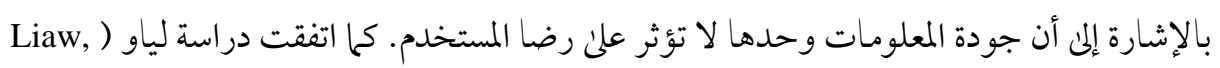
2007) ودراسة رامايه ولي (Ramayah \& lee, 2012) ودراسة دريهيب وبصير وفابيل ( Dreheeb, ؤن

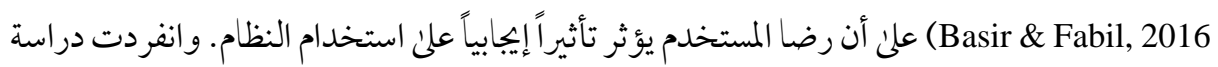


يوسب (Yosep, 2015) بإشارتها إلن أن رضا المستخدم يتأثر تأثراً إيجابياً بالمنفعة الصافية التي يجقتها

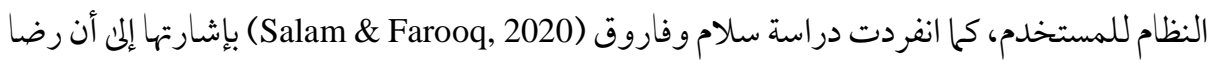
المستخدم واستخدام النظام يتأثران تأثراً إيجابياً بالمنفعة الصافية التي يجققها النظام للمستخدم.

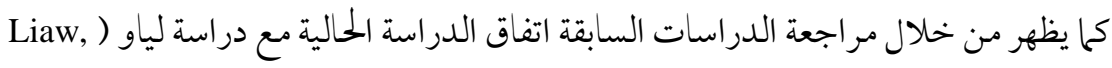

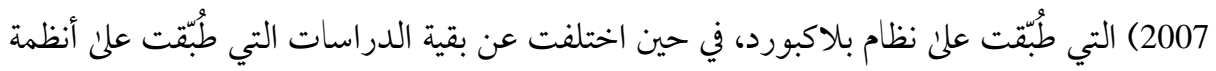

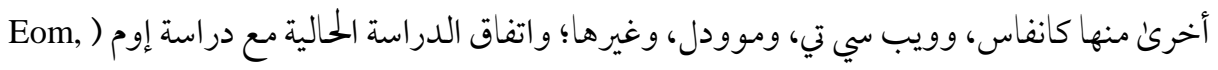
2014)، ودراسة دريهيب وبصير وفابيل (Dreheeb, Basir \& Fabil, 2016)، ودراسة أوهلياتي وعباس (Ohliati \& Abbas, 2019) في تطبيقها علن طلبة في مرحلة الدراسات العليا. كما اتفتت

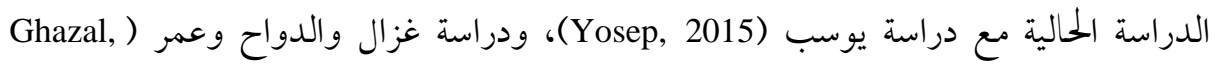

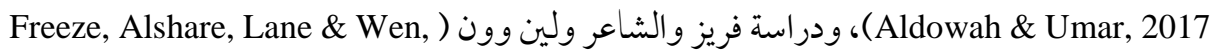
2019)، ودراسة سلام وفاروق (Salam \& Farooq, 2020) في تطبيقها علن طلبة يدرسون عن بعد؛

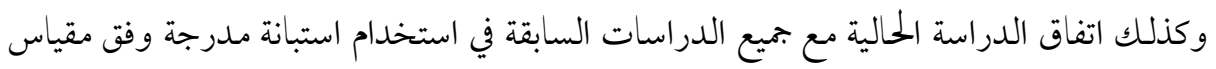

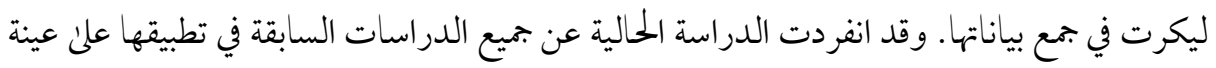

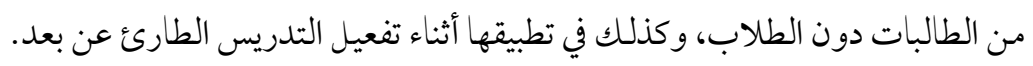

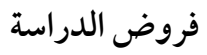

تستند الدراسة علن نموذج نجاح المعلومات لديلون ومكلين المحدث (أنظر شكل ؟)، كإطار

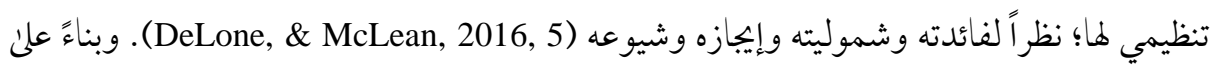

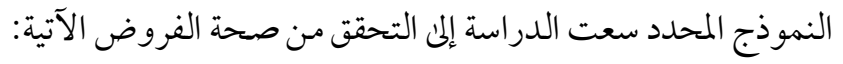

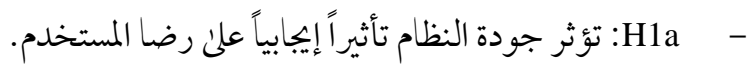

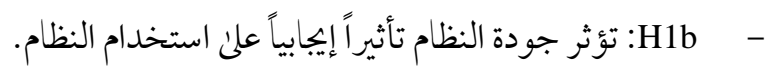

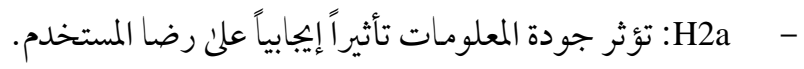
H2b - ت تؤثر جودة المعلومات تأثيراً إيجابياً علن استخدام النظام. 
H3a - تؤثر جودة الخدمة تأثيراً إيجابياً على رضا المستخدم. -

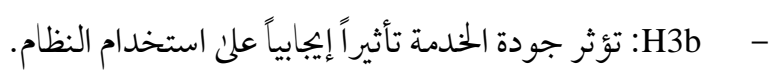

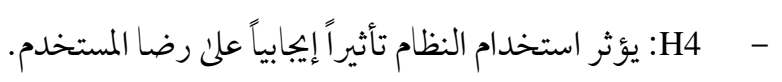
H5 H7 - يؤثر رضا المستخدم تأثيراً إيجابياً على المنفعة الصافية.

أهداف الدراسة - n - n

هدفت الدراسة إلى تقصي درجة رضا طالبات الدراسات العليا في تخصص تقنيات التعليم عن نظام بلاكبورد واستخدامه في تدريسهن الطارئ عن بعد في ضوء العوامل التي حددها نموذج نجاح نظام المعلومات لديلون ومكلين. أهمية الدراسة

تظهر أهمية هذه الدراسة من خلال النقاط الآتية:

- - مواكب هذه الدراسة أزمة فيروس كورونا المستجد التي أثرت علن جميع نظم التعليم في أنحاء العالر، ولذا يمكن أن تكشف من خلال نتائجها عن جو انب مرتبطة برضا المستخدم عن نظم

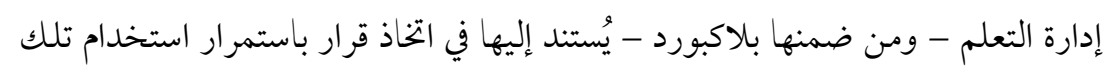

$$
\text { النظم أو إيقافها عند تطبيق التدريس الطارئ عن بعد. }
$$

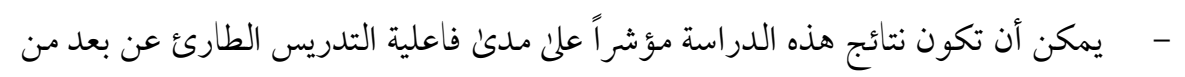

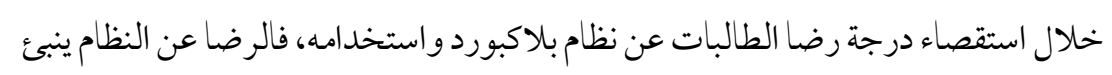
- بطريقة أو أخرى - عن درجة الرضاعن تجربة التدريس الطارئ عن بعد. - تقدم هذه الدراسة علن صوت الطالب (Student voice)؛ أي القيم والآراء والمعتقدات ووجهات النظر والخلفيات الثقافية للطلاب، والأساليب والتقنيات التعليمية التي تعتمد علن اختيارات الطلاب أنفسهم، واهتماماتهم، وشغفهم، وطموحهم. ويمكن أن يكون صوت 
الطالب بديلاً لأشكال الحوكمة أو التدريس المعتادة التي يتخذ فيها المسؤولون قرارات أحادية مع مشاركة قليلة من الطلاب، أو دونها.

طُبقت الدراسة بعد انتهاء أعمال الفصل الدراسي الثاني من العام الدراسي (1441هـ - 2020م)، وذلك لضمان مرور الطالبات بخبرة التدريس الطارئ عن بعد عن طريق بلاكبورد لفترة تسمح لهن

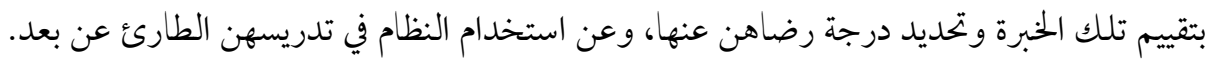

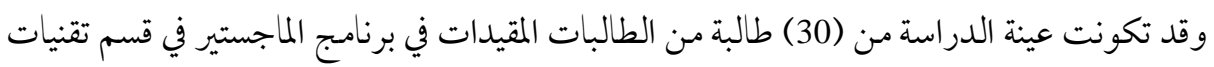
التعليم الذي تنتمي إليه الباحثة، واقتصرت الدراسة علن تقصي درجة رضا رضا الطالبات عن نظام بلاكبورد

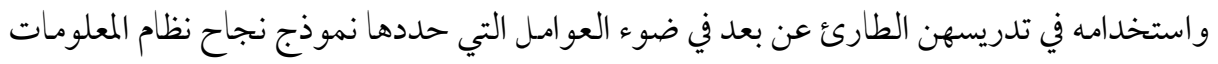

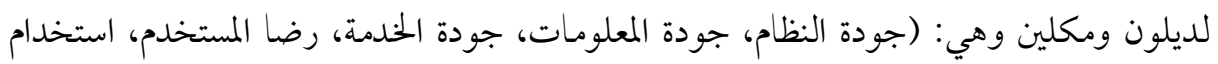

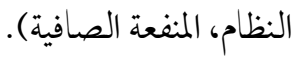
مصطلحات الدراسة

$$
\text { تناولت الدراسة عدداً من المصطلحات التي سُّعَّف فيما يأتي: }
$$

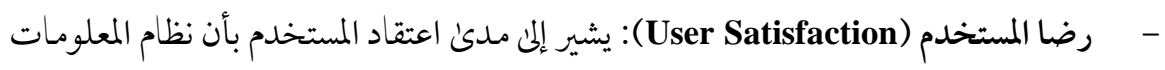

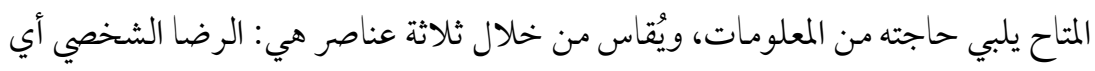

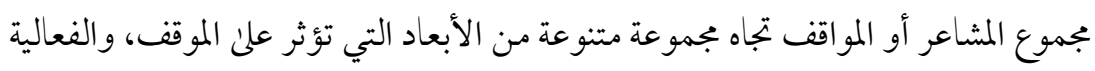

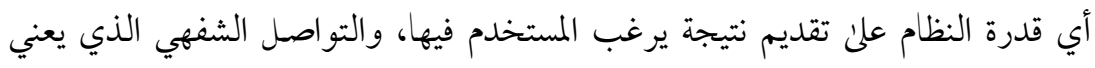

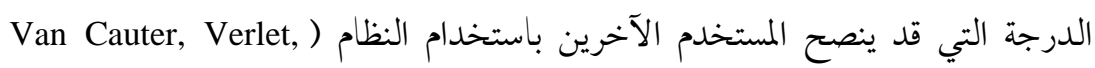
.(Snoeck, \& Crompvoets, 2017, 44 ويُقصَد به في هذه الدراسة رضا طالبات الدراسات العليا في تخصص تقنيات التعليم عن نظام بلاكبورد واستخدامه في تدريسهن الطارئ عن بعد في ضوء العوامل التي حددها نموذج الدراسة، 
ويُقاس بالدرجة التي يحصلن عليها في استبانة رضا الطالبات عن نظام بلاكبورد واستخدامه في تدريسهن الطارئ عن بعد.

- - نظام بلاكبورد (Blackboard System): نظام إدارة تعلم يوفر من خلال واجهة حديثة وسريعة الاستجابة تجربة تعليم وتعلم أكثر سهولة وقوة وكفاءة من نظم إدارة التعلم المعتادة. ويتيح النظام للمعلم والمتعلم إنجاز مهاتهها بسرعة وسهولة من خلال أدوات قوية سهلة تساعد كليها علئ البقاءمنظاً، مع تطبيق الإجراءات بيسر، والانخر اطمع المحتوى و التفاعل فيها بينها. و وإضافة إلى ما سبق يتو افر للنظام تطبيق متو افق مع جميع الأجهزة المتنقلة وتطبيقاتها يتيح عمليتي التعليم و التعلم في أي وقت ومكان (Blackboard, 2020b).

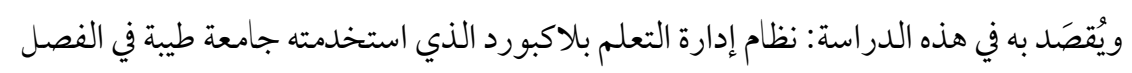
الدراسي الثاني من العام الدراسي (1441ه - 2020م)، لتفعيل التعلم عن بعد؛ التزامًا بالإجراءات

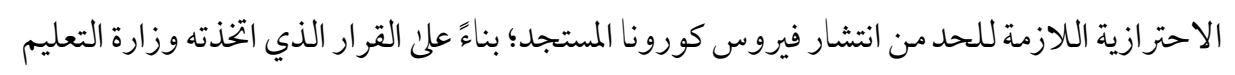

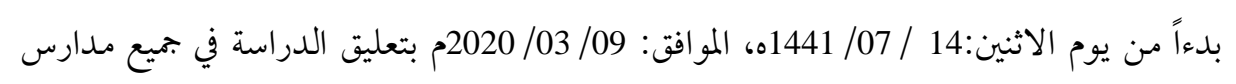
ومؤسسات التعليم العام والأهلي والجحامعي والفني في المملكة العربية السعودية. - - التدريس الطارئ عن بعد (Emergency Remote Teaching): يشير إلى تحولِ مؤقتٍ من

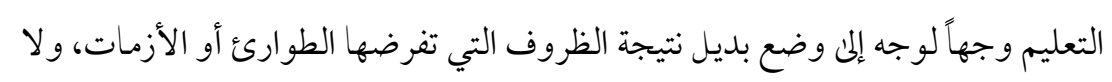

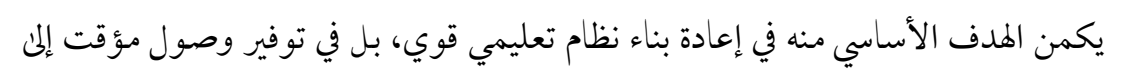
التعليم، ودعمه بطريقةٍ تتسم بسرعة الإعداد علن نحو موثوق به أثناء الطو ارئ أو الأزمات

.(Hodges, Moore, Lockee, Trust, \& Bond, 2020) ويُقصَد به في هذه الدراسة: نمط التعليم الذي فُعْل بدءاً من يوم الاثنين: 14/ 14 / 1441ه،

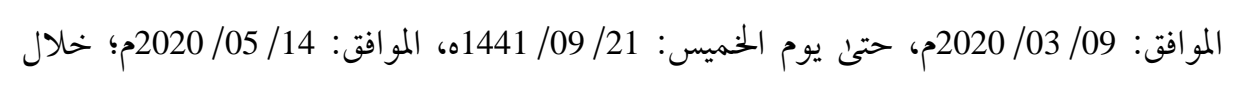
الفصل الدراسي الثاني من العام الدراسي (1441ه - 2020م)، من خلال نظام بلاكبورد، واعتّمد فيه 
علن الفصول الافتراضية، إضافة إلى أدوات النظام الأخرى مثل: الواجبات، والاختبارات، ولوحات النقاش، والمدونات.

- - مبوذج نجاح نظام المعلومات لديلون ومكلين ( DeLone and McLean's Information System Success Model من خلال تحديد ووصف وتفسير العلاقات بين ستة عوامل حاسمة للنجاح، تُقييم نظم المعلومات عادة من خلالها وهي: جودة النظام، وجودة المعلومات، وجودة الخدمة، ورضا المستخدم، والاستخدام، والمنفعة الصافية. وقد طور ديلون ومكلين النموذج في صورته

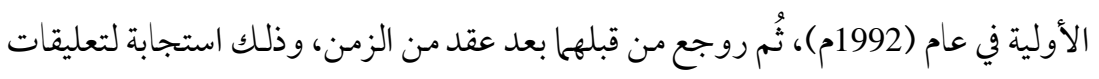

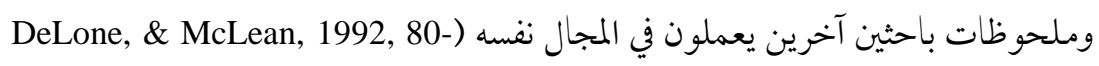
.(87; DeLone, \& McLean, 2003, 23-24 ويُقصَد به في هذه الدراسة نموذج نجاح نظام المعلومات الذي استندت الدراسة في بنائه على العوامل التي حددها ديلون ومكلين في نموذجهها وهي: جودة النظام، جودة المعلومات، جودة الخدمة، رضا المستخدم، استخدام النظام، المنفعة الصافية، لاستقصاء درجة رضا طالبات الدراسات العليا في تخصص تقنيات التعليم عن نظام بلاكبو رد واستخدامه في تدريسهن الطارئ عن بعد. منهج الدراسة

اتبعتِ الدراسة المنهج الوصفي الذي يسعى إلى وصف ظاهرة أو مشكلة ما، وتصويرها كمياً عن طريق جمع بيانات ومعلومات مقننة عنها، ثم تصنيف تلك المعلومات، وتحليلها، وتفسيرها؛ للخروج بفهم أعمق للظاهرة أو المشكلة موضوع الدراسة (Shields \& Rangarajan, 2013). مجتمع الدراسة وعينتها

يتكون بجتمع الدراسة من طالبات الدراسات العليا المسجلات بمرحلة الماجستير في تخصص تقنيات التعليم، في كلية التربية، بجامعة طيبة بالمدينة المنورة، خلال الفصل الدراسي الثاني من العام الجحامي (1441هـ - 2020م)، والبالغ عددهن (39) طالبة، استُبعدت طالبة واحدة منهن نظراً لكونها 
معتذرة عن الدراسة. وقد أرسل رابط استبانة رضا طالبات الدراسات العليا في تخصص تقنيات التعليم عن نظام بلاكبوردو واستخدامه في تدريسهن الطارئ عن بعد عقب الانتهاء من إعدادها من خلال نماذج غوغل وتقنينه إلى جميع الطالبات المستمرات في دراستهن وعددهن (38) طالبة، فاستجابت (30) طالبة منهن كوَّن عينة الدراسة. أداة الدراسة

استخدمت الدراسة استبانة استندت إلى نموذج نجاح نظام المعلومات لديلون ومكلين لتقصي درجة رضا طالبات الدراسات العليا في تحصص تقنيات التعليم عن نظام بلاكبورد واستخدامه في تدريسهن الطارئ عن بعد. وقد بُنيت الاستبانة بعد مراجعة الدراسات السابقة المرتبطة بموضوع الدراسة مثل دراسة ياكوبو وداسوكي (Yakubu \& Dasuki, 2018)، ودراسة فريز والشاعر ولين Salam \& Farooq, ) وون (Freeze, Alshare, Lane \& Wen, 2019) ودراسة سلام وفاروق 2020). وتكونت في صورتها الأولية من (30) عبارة اندرجت تحت (6) عوامل هي: جودة النظام، جودة المعلومات، جودة الخدمة، رضا المستخدم، استخدام النظام، المنفعة الصافية؛ بواقع (5) عبار ات تحت كل عامل. ودرِّجَت وفق مقياس ليكرت الخحاسي علن النحو الآتي: (موافقة بشدة - موافقة -

$$
\text { مو افقة إلى حد ما - غير موافقة - غير موافقة بشدة). }
$$

وحسب صدق محتوى الاستبانة من خلال عرضها على عددمن المحكمين في تخصص: تقنيات

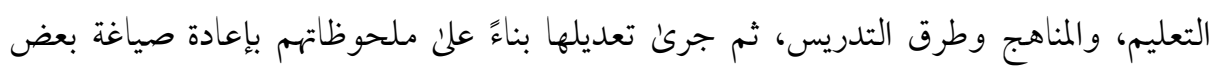

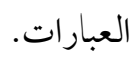

كما حسب صدق الاستبانة من خلال حساب صدق الاتساق الداخلي لتحديد معاملات ارتباط بيرسون (Pearson) لقياس العلاقة بين عوامل استبانة درجة الرضا عن نظام بلاكك بورد واستخدامه في التدريس الطارئ عن بعد، بالدرجة الكلية للاستبانة. وكما يظهر في الجمدول التالي فقد كانت العوامل ذات معاملات ارتباط دالة عند مستوى (0.01). 
جدول (1): معاملات ارتباط عوامل استبانة درجة الرضا عن نظام بلاك بورد واستخدامه في التدريس الطارئ عن بعد بالدرجة الكلية للاستبانة

\begin{tabular}{|c|c|}
\hline معامل الارتباط & العوامل \\
\hline *** 0.8849 & جودة النظام \\
\hline ***0.8229 & جودة المعلومات \\
\hline **** 0.7074 & جودة الخدمة \\
\hline ***6.9095 & رضا المستخدم \\
\hline *** 0.9223 & الاستخدام \\
\hline ***9391 & المنفعة الصافية \\
\hline
\end{tabular}

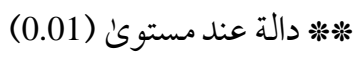

أما ثبات الاستبانة فقد حُسِبَ من خلال تحديد معامل ألفا كرونباخ (Cronbach's Alpha)، وكما يظهر في الجحدول التالي فقد تراوحت معاملات ثبات العوامل بين: (0.92 - 0.95)، كما بلغ الثبات الكلي للاستبانة (0.97)، وهي معاملات تدل على صلاحية الاستبانة للاستخدام. جدول (2): معاملات ثبات ألفا كرونباخ لعوامل الاستبانة

\begin{tabular}{|c|c|c|}
\hline معامل الارتباط & عدد العبارات & العوامل \\
\hline 0.92 & 5 & جودة النظام \\
\hline 0.87 & 5 & جودة المعلومات \\
\hline 0.87 & 5 & جودة الخدمة \\
\hline 0.95 & 5 & رضا المستخدم \\
\hline 0.92 & 5 & استخدام النظام \\
\hline 0.92 & 5 & المنفعة الصافية \\
\hline 0.97 & 30 & الثبات الكلي للاستبانة \\
\hline
\end{tabular}

http://dx.doi.org/10.29009/ijres.3.4.6 


\section{نتائج الدراسة ومناقشتها}

سعت الباحثة للتحقق من صحة كل فرض من فروض الدراسة على حدة باستخدام تحليل

الانحدار الخطي كما ياتي:

- التحقق من صحة الفرض الأول - أونصه: (H1a: تؤثر جودة النظام تأثيراً إيجابياً على رضا

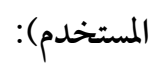

جدول (3): نتائج تحليل الانحدار الخطي لمعرفة مدى تأثير جودة النظام على رضا المستخدم

\begin{tabular}{|c|c|c|c|c|c|}
\hline مستوى & قيمة ف & $\begin{array}{c}\text { معامل التحديد } \\
\left(\mathbf{R}^{2}\right)\end{array}$ & $\begin{array}{c}\text { معامل الارتباط } \\
\text { (R) }\end{array}$ & نوع العامل & العوامل \\
\hline \multirow[t]{2}{*}{0.000} & \multirow[t]{2}{*}{760.97} & \multirow[t]{2}{*}{0.731} & \multirow[t]{2}{*}{0.855} & & جودة النظام \\
\hline & & & & تابع & رضا المستخدم \\
\hline
\end{tabular}

يتضح من الجلدول أن قيمة (ف) دالة عند مستونى (0.01)، مما يشير إلى وجود تأثير ذي دلالة

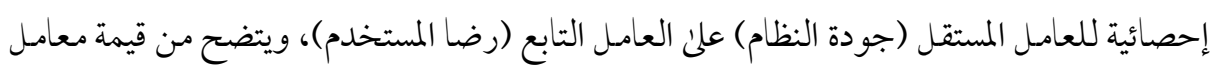
الارتباط (R) أن هذا التأثير كان طردياً (إيجابياً)، أي أنه كلما ارتفع مستوكا جودة نظام بلاكبورد من إسن وجهة نظر أفراد العينة، ارتفعت درجة رضا المستخدم عنه.

كما يتضح من الجدول أن قيمة معامل التحديد (R2) بلغت (0.731)، أي أن العامل المستقل (جودة النظام) يفسر (73.1\%) من التباين الكلي لدرجة رضا المستخدم عن نظام بلاكبورد، ويتنبأ بدرجة رضا المستخدم عن نظام بلاكبورد بنسبة ((73.1\%). . وبذلك يُقبل الفرض الأول - أ. 
- - - التحقق من صحة الفرض الأول - ب ونصه: (H1b: تؤثر جودة النظام تأثيراً إيجابياً على

$$
\text { (الاستخدام): (4) (ب) }
$$

جدول (4): نتائج تحليل الانحدار الخطي لمعرفة مدى تأثير جودة النظام على استخدامه

\begin{tabular}{|c|c|c|c|c|c|}
\hline مستوى & قيمة ف & معامل التحديد & $\begin{array}{c}\text { معامل الارتباط } \\
\text { (R) }\end{array}$ & نوع العامل & العوامل \\
\hline \multirow[t]{2}{*}{0.000} & \multirow[t]{2}{*}{33.947} & \multirow[t]{2}{*}{0.548} & \multirow[t]{2}{*}{0.740} & & جودة النظام \\
\hline & & & & تابع & استخدام النظام \\
\hline
\end{tabular}

يتضح من الجلدول أن قيمة (ف) دالة عند مستوئ (0.01)، مما يشير إلى وجود تأثير ذي دلالة

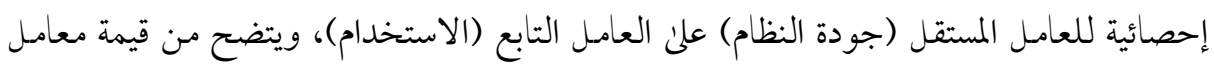
الارتباط (R) أن هذا التأثير كان طردياً (إيجابياً)، أي أنه كلم) ارتفع مستوكن جودة نظام بلاكبورد من وجهة نظر أفراد العينة، ارتفعت درجة استخدامه.

كما يتضح من الجمدول أن قيمة معامل التحديد (R2) بلغت (0.548)، أي أن العامل المستقل (جودة النظام) يفسر (54.8٪) من التباين الكلي لدرجة استخدام نظام بلاكبورد،، ويتبأ بدرجة استخدام

$$
\text { نظام بلاك بورد بنسبة (54.8٪). وبذلك يُقبل الفرض الأول - ب. }
$$

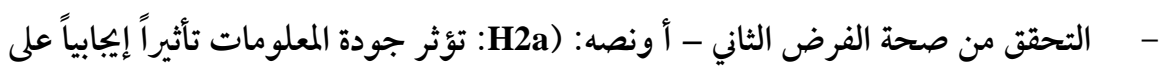

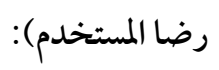

\begin{tabular}{|c|c|c|c|c|c|}
\hline مستوى الدلالة & قيمة ف & $\begin{array}{c}\text { معامل التحديد } \\
\left(\mathbf{R}^{2}\right)\end{array}$ & $\begin{array}{c}\text { معامل الارتباط } \\
\text { (R) }\end{array}$ & نوع العامل & العوامل \\
\hline \multirow[t]{2}{*}{0.000} & \multirow[t]{2}{*}{23.070} & \multirow[t]{2}{*}{0.452} & \multirow[t]{2}{*}{0.672} & & جودة المعلومات \\
\hline & & & & تابع & رضا المستخدم \\
\hline
\end{tabular}

جدول (5): نتائج تحليل الانحدار الخطي لمعرفة مدى تأثير جودة المعلومات على رضا المستخدم

يتضح من الجحدول أن قيمة (ف) دالة عند مستوى (0.01)، مما يشير إلنى وجود تأثير ذي دلالة إحصائية للعامل المستقل (جودة المعلومات) علن العامل التابع (رضا المستخدم)، ويتضح من قيمة 
معامل الارتباط (R) أن هذا التأثير كان طردياً (إيجابياً)، أي أنه كلما ارتفع مستوى جودة المعلومات علن. نظام بلاكبورد من وجهة نظر أفراد العينة، ارتفعت درجة رضا المستخدم.

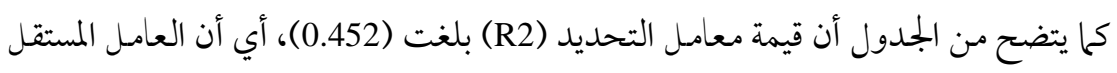
(جودة المعلومات) يفسر (45.2/) من التباين الكلي لدرجة رضا المستخدم عن نظام بلاكبورد، ويتنباً

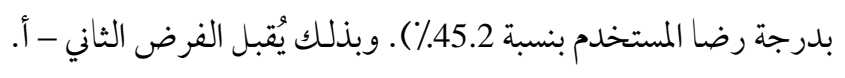

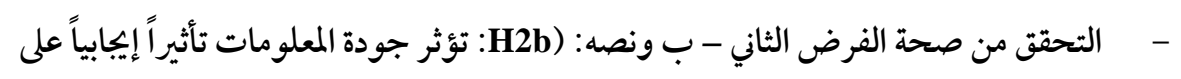
الاستخدام):

\begin{tabular}{|c|c|c|c|c|c|}
\hline مستوى & قيمة ف & $\begin{array}{c}\text { معامل التحديد } \\
\left(\mathbf{R}^{2}\right)\end{array}$ & $\begin{array}{c}\text { معامل الارتباط } \\
\text { (R) }\end{array}$ & العامل & العوامل \\
\hline \multirow{2}{*}{0.000} & \multirow{2}{*}{34.388} & \multirow{2}{*}{0.551} & \multirow{2}{*}{0.742} & مستقل & جودة المعلومات \\
\hline & & & & تابع & استخدام النظام \\
\hline
\end{tabular}

يتضح من الجدول أن قيمة (ف) دالة عند مستون (0.01)، ما يشير إلى وجود تأثير ذي دلالة

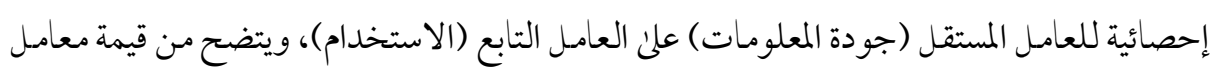

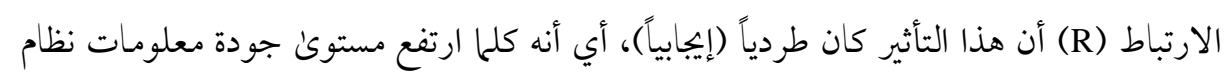
بلاكبوردمن وجهة نظر أفراد العينة، ارتفعت درجة استخدامه.

كما يتضح من الجدول أن قيمة معامل التحديد (R2) بلغت (0.551)، أي أن العامل المستقل

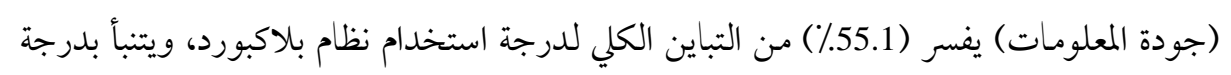

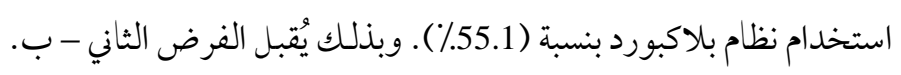


- - التحقق من صحة الفرض الثالث - أونصه: (H3a: تؤثر جودة الخدمة تأثيراً إيجابياً على رضا

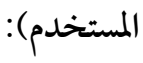

جدول (7) : نتائج تحليل الانحدار الخطي لمعرفة مدى تأثير جودة الخدمة على رضا المستخدم

\begin{tabular}{|c|c|c|c|c|c|}
\hline مستوى & قيمة ف & معامل التحديد & $\begin{array}{c}\text { معامل الارتباط } \\
\text { (R) }\end{array}$ & نوع العامل & العوامل \\
\hline \multirow{2}{*}{0.005} & \multirow{2}{*}{9.391} & \multirow{2}{*}{0.251} & \multirow{2}{*}{0.501} & مستقل & جودة الخدمة \\
\hline & & & & تابع & رضا \\
\hline
\end{tabular}

يتضح من الجحدول أن قيمة (ف) دالة عند مستوى (0.01)، مما يشير إلى وجود تأثير ذي دلالة إحصائية للعامل المستقل (جودة الخدمة) علن العامل التابع (رضا المستخدم)، ويتضح من قيمة معامل الارتباط (R) أن هذا التأثير كان طردياً (إيجابياً)، أي أنه كلما ارتفع مستوى جودة الحندمة على نظام بلاكبوردمن وجهة نظر أفراد العينة، ارتفعت درجة رضا المستخدم. كما يتضح من الجدول أن قيمة معامل التحديد (R2) بلغت (0.251)، أي أن العامل المستقل (جودة الخدمة) يفسر (25.1\%) من التباين الكلي لدرجة رضا المستخدم عن نظام بلاكبورد، ويتنباً بدرجة رضا المستخدم بنسبة (25.1٪). وبذلك يُقبل الفرض الثالث - أ.

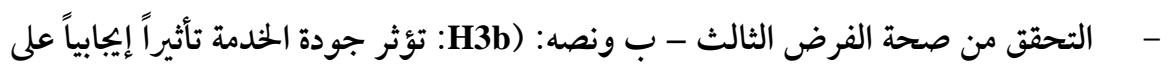

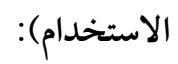
جدول (8): نتائج تحليل الانحدار الخطي لمعرفة مدى تأثير جودة الخدمة على الاستخدام

\begin{tabular}{|c|c|c|c|c|c|}
\hline مستوى & قيمة ف & $\begin{array}{c}\text { معامل التحديد } \\
\left(\mathbf{R}^{2}\right)\end{array}$ & $\begin{array}{c}\text { معامل الارتباط } \\
\text { (R) }\end{array}$ & نوع العامل & العوامل \\
\hline \multirow[t]{2}{*}{0.001} & \multirow[t]{2}{*}{13.105} & \multirow[t]{2}{*}{0.319} & \multirow[t]{2}{*}{0.565} & & جودة الخدمة \\
\hline & & & & تابع & استخدام النظام \\
\hline
\end{tabular}

يتضح من الجلدول أن قيمة (ف) دالة عند مستوى (0.01)، مما يشير إلى وجود تأثير ذي دلالة

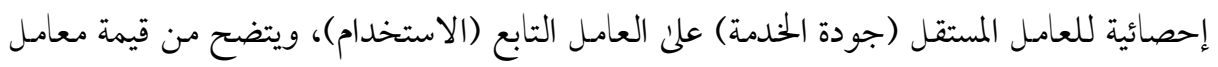


الارتباط (R) أن هذا التأثير كان طردياً (إيجابياً)، أي أنه كلما ارتفع مستوى جودة الخدمة علن نظام بلاكبوردمن وجهة نظر أفراد العينة، ارتفت درجة الاستخدام.

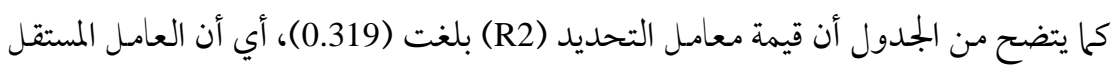

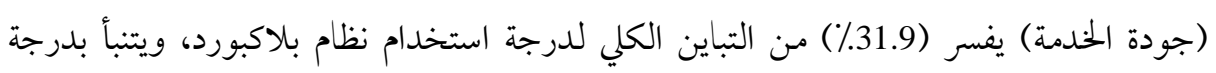

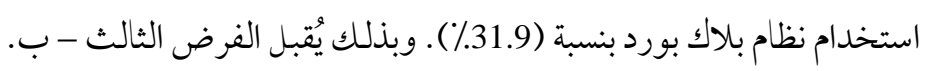

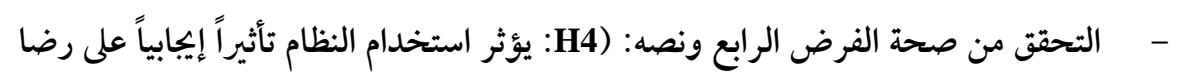
المستخدم):

\begin{tabular}{|c|c|c|c|c|c|}
\hline مستوى & قيمة ف & $\begin{array}{c}\text { معامل التحديد } \\
\left(\mathbf{R}^{2}\right)\end{array}$ & $\begin{array}{c}\text { معامل الارتباط } \\
\text { (R) }\end{array}$ & نوع العامل & العوامل \\
\hline \multirow[t]{2}{*}{0.000} & \multirow[t]{2}{*}{66.446} & \multirow[t]{2}{*}{0.704} & \multirow[t]{2}{*}{0.893} & مستقل & استخدام النظام \\
\hline & & & & تابع & رضا المتخخدم \\
\hline
\end{tabular}

يتضح من الجدول أن قيمة (ف) دالة عند مستوي (0.01)، ما يشير إلنى وجود تأثير ذي دلالة

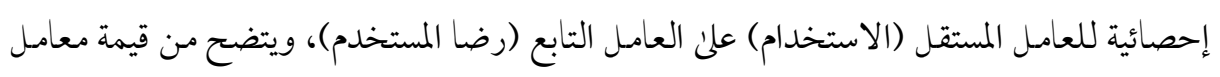

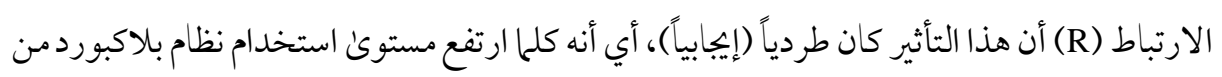

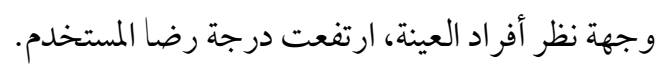

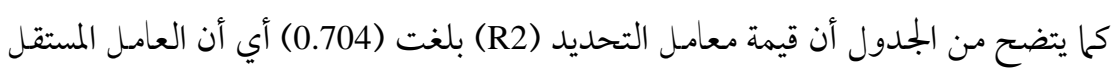

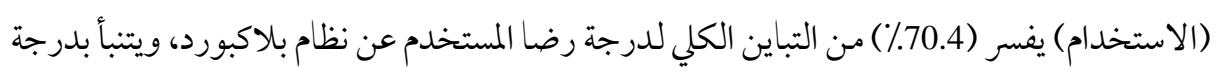
رضا المستخدم بنسبة (70.4/). وبذلك يُقبل الفرض الرابع. 
- التحقق من صحة الفرض الخامس ونصه: (H5: يؤثر استخدام النظام تأثيراً إيجابياً على المنفعة

الصافية):

جدول (10): نتائج تحليل الانحدار الخطي لمعرفة مدى تأثير الاستخدام على المنفعة الصافية

\begin{tabular}{|c|c|c|c|c|c|}
\hline مستوى & قيمة ف & معامل التحديد & $\begin{array}{c}\text { معامل الارتباط } \\
\text { (R) }\end{array}$ & نوع العامل & العوامل \\
\hline \multirow[t]{2}{*}{0.000} & \multirow[t]{2}{*}{95.128} & \multirow[t]{2}{*}{0.773} & \multirow[t]{2}{*}{0.879} & & استخدام النظام \\
\hline & & & & تابع & المنفعة الصافية \\
\hline
\end{tabular}

يتضح من الجحدول أن قيمة (ف) دالة عند مستوئ (0.01)، مما يشير إلى وجود تأثير ذي دلالة

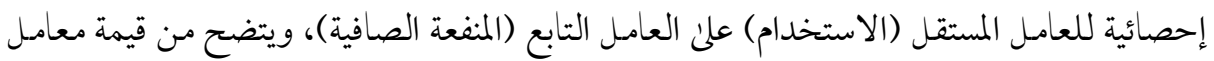
الارتباط (R) أن هذا التأثير كان طردياً (إيجابياً)، أي أنه كلما ارتفع مستوى الاستخدام من وجهة نظر أفراد العينة، ارتفعت درجة المنفعة الصافية. كما يتضح من الجدول أن قيمة معامل التحديد (R2) بلغت (0.773)، أي أن العامل المستقل (الاستخدام) يفسر (77.3٪) من التباين الكلي لدرجة المنفعة الصافية، ويتنبأ بدرجة المنفعة الصافية بنسبة (77.3\%). وبذلك يُقبل الفرض الخامس. - التحقق من صحة الفرض السادس ونصه: (H6) يؤثر رضا المستخدم تأثيراً إيجابياً على المنفعة

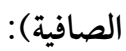

جدول (11): نتائج تحليل الانحدار الخطي لمعرفة مدى تأثير رضا المستخدم على المنفعة الصافية

\begin{tabular}{|c|c|c|c|c|c|}
\hline مستوى & قيمة ف & $\begin{array}{c}\text { معامل التحديد } \\
\text { (R2) }\end{array}$ & $\begin{array}{c}\text { معامل الارتباط } \\
\text { (R) }\end{array}$ & العامل & العوامل \\
\hline \multirow{2}{*}{0.000} & \multirow{2}{*}{59.945} & \multirow{2}{*}{0.682} & \multirow{2}{*}{0.826} & مستقل & رضا المستخدم \\
\hline & & & & تابع & المنفعة الصافية \\
\hline
\end{tabular}


يتضح من الجحدول أن قيمة (ف) دالة عند مستوى (0.01)، مما يشير إلى وجود تأثير ذي دلالة إحصائية للعامل المستقل (رضا المستخدم) علن العامل التابع (المنفعة الصافية)، ويتضح من قيمة معامل الارتباط (R) أن هذا التأثير كان طردياً (إيجابياً)، أي أنه كلما ارتفع مستون رضا المستخدم من وجهة نظر أفراد العينة، ارتفعت درجة المنفعة الصافية.

كما يتضح من الجدول أن قيمة معامل التحديد (R2) بلغت (0.682)، أي أن العامل المستقل (رضا المستخدم) يفسر (68.2\%) من التباين الكلي لدرجة المنفعة الصافية، ويتنبأ بدرجة المنفعة الصافية بنسبة (68.2\%). وبذلك يُقبل الفرض السادس. وبصورة بجملة، يلخص الجدول الآتي نتائج فروض الدراسة حول العلاقات الارتباطية بين العوامل المؤثرة على رضا طالبات الدراسات العليا في تخصص تقنيات التعليم عن نظام بلاكبورد واستخدامه في تدريسهن الطارئ عن بعد. جدول (12): نتائج فروض الدراسة حول العلاقات الارتباطية بين العوامل المؤثرة على رضا طالبات الدراسات العليا في

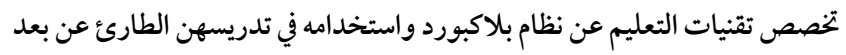

\begin{tabular}{|c|c|c|}
\hline النيجة & نصى الفرض & p \\
\hline 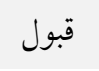 & تؤثر جودة النظام تأثيراً إيجابياً علن رضا المستخدم & $\mathrm{H} 1 \mathrm{a}$ \\
\hline 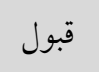 & تؤثر جودة النظام تأثيراً إيجابياً على استخدام النظام & $\mathrm{H} 1 \mathrm{~b}$ \\
\hline 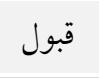 & تؤثر جودة المعلومات تأثيراً إيجابياً علن رضا المستخدم & $\mathrm{H} 2 \mathrm{a}$ \\
\hline 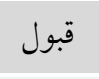 & تؤثر جودة المعلومات تأثيراً إيجابياً علن استخدام النظام & $\mathrm{H} 2 \mathrm{~b}$ \\
\hline 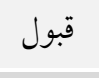 & تؤثر جودة الخدمة تأثيراً إيجابياً علن رضا المستخدم & $\mathrm{H} 3 \mathrm{a}$ \\
\hline 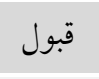 & تؤثر جودة الخدمة تأثيراً إيجابياً على استخدام النظام & $\mathrm{H} 3 \mathrm{~b}$ \\
\hline 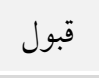 & يؤثر استخدام النظام تأثيراً إيجابياً علن رضا المستخدم & $\mathrm{H} 4$ \\
\hline قبول & يؤثر استخدام النظام تأثيراً إيجابياً علن المنفعة الصافية & H5 \\
\hline 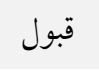 & يؤثر رضا المستخدم تأثيراً إيبابياً علن المنفعة الصافية & H6 \\
\hline
\end{tabular}


ويظهر من خلال الجدول (12) قبول جميع فروض الدراسة. وتشير النتائج بصورة عامة إلى أن جودة النظام، وجودة المعلومات، وجودة المدمة، والمنغعة الصافية كانت مؤشرات منبئة عن درجة رضا طالبات الدراسات العليا في تخصص تقنيات التعليم عن نظام بلاكبور د؛و ويدعم ذلك العلاقة الارتباطية

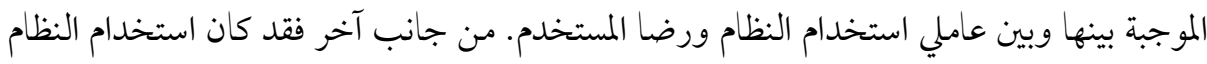
بدورهمؤشراً منبئً بدرجة رضا طالبات الدراسات العليا في تخصص تقنينات التعليم عن نظام بلاكبو ردي؛ ويدعم ذلك العلاقة الارتباطية الموجبة بينه وبين رضا المستخدم.

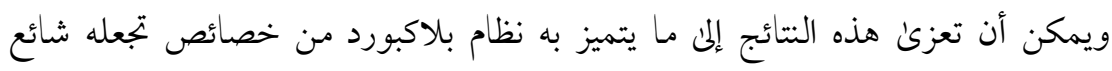

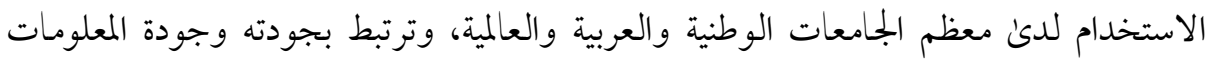
و الخدمة المقدمة من خلاله والمنفعة الصافية التي يجققها المستخدم عند استخدامه، والتي تؤثر من جانبها علن استخدامه ورضا المستخدم عنه، ومنها سهولة الوصول: إذ يسمح النظام للمستخدم بالتواصل

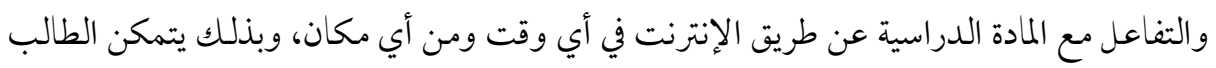

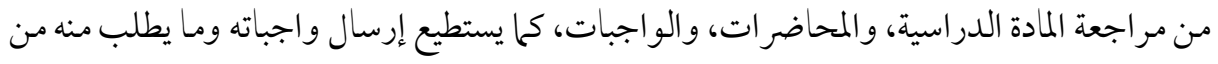
مشروعات إلم معلمه حالما ينتهي من إنجازها. وتوفير تغذية راجعة سريعة ومستمرة: إذ يوفر النظام

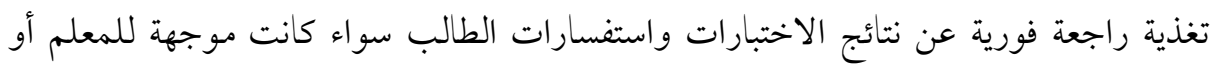
للأقران، عن طريق لوحة النقاش، أو البريد الالكتروني وغيرها. وتحسين عملية الاتصال وتسهيلها:

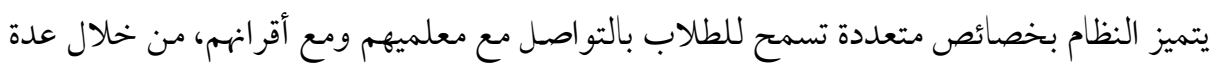

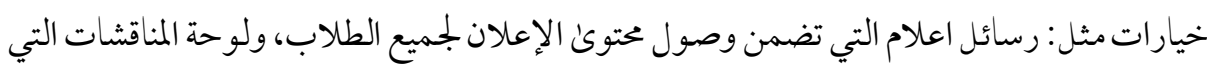
تساعد علن تطوير الزمالة بين الطلاب، وتوفر لمم وسائل دعم إضافية من خلال تشجيعهم علن الرد الردان

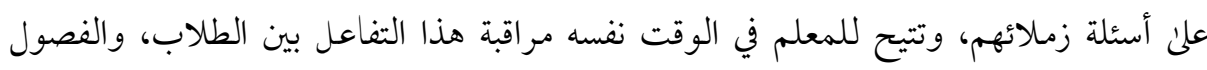

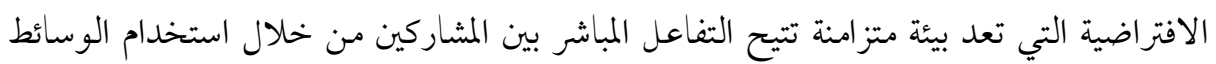

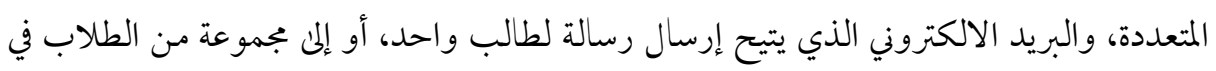

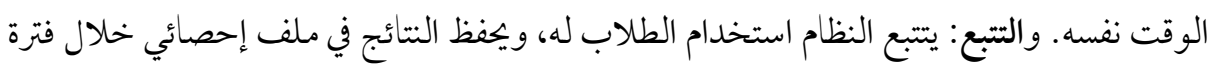


التعليم، ويستطيع المعلم بذلك الحصول علن معلومات إحصائية عن جميع طلابه، أو عن مجموعة منهم،

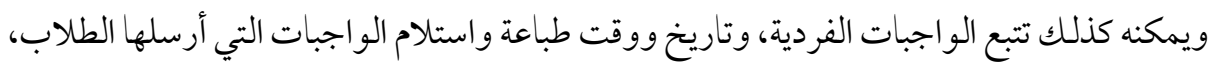

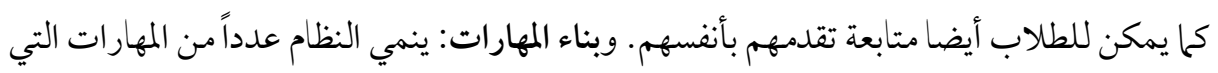

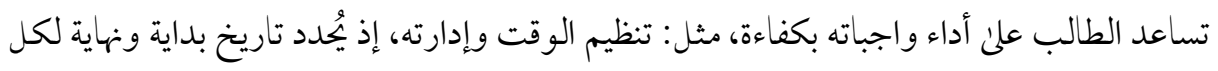

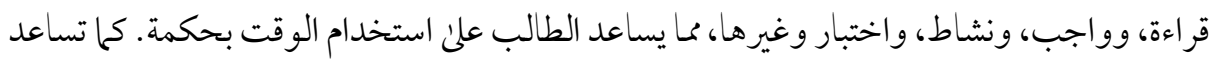

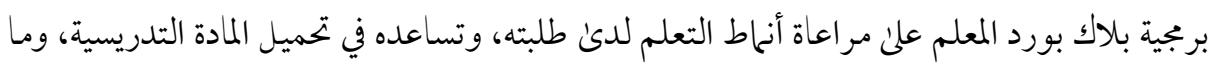

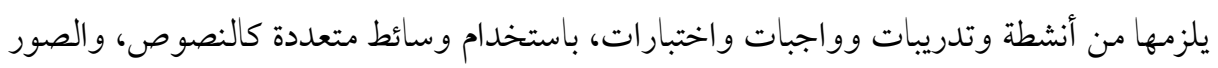

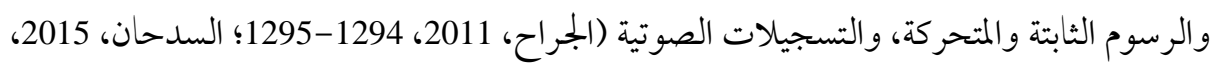
. (239-238

وتتفق هذه النتائج فيما يرتبط بتأثير جودة النظام، وجودة المعلومات، وجودة الحدمة علن رضا

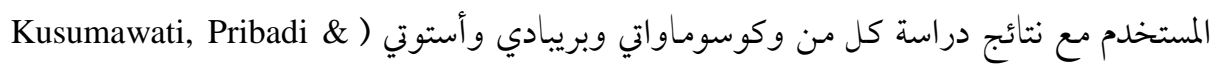

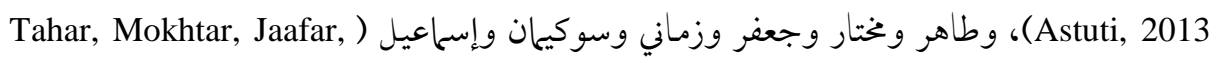
Yakubu (Zamani, Sukiman, \& Ismail, 2013 .(\& Dasuki, 2018

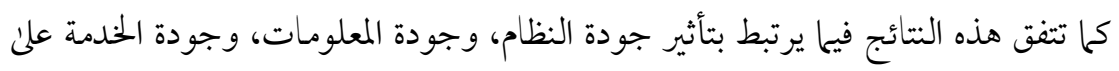

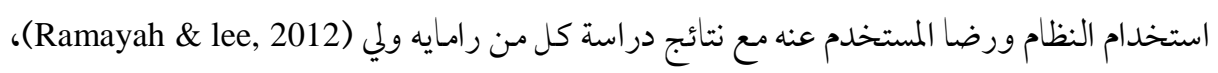

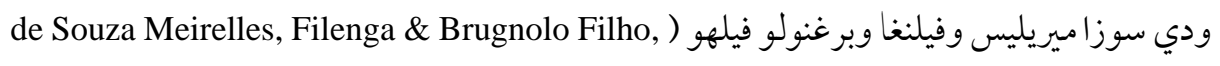

وتتفق هذه النتائج فيا يرتبط بتأثير جودة النظام علن رضا المستخدم مع نتائج دراسة كل من

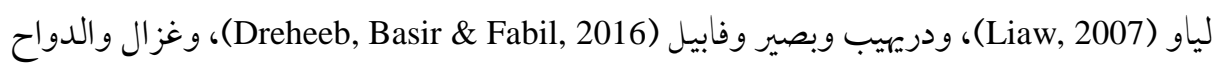
وعمر (Ghazal, Aldowah \& Umar, 2017). 
وتتفق هذه النتائج كذلك فيا يرتبط بتأثير جودة المعلومات علن استخدام النظام مع نتائج دراسة كل من فريز والشاعر ولين وون (Freeze, Alshare, Lane \& Wen, 2019)، وكورت ( Kurt, 2019)، فيها وتتفق هذه النتائج فيا يرتبط بتأثير جودة المعلومات علن رضا المستخدم مع نتائج دراسة كل من إوم (Eom, 2014)، وغزال والدواح وعمر (Ghazal, Aldowah \& Umar, 2017)، وكورت .(Kurt, 2019) وتتفق هذه النتائج فيها يرتبط بتأثير جودة الخدمة علن رضا المستخدم مع نتائج دراسة كل من ياكوبو وداسوكي (Yakubu \& Dasuki, 2018)، وأوهلياتي وعباس (Ohliati \& Abbas, 2019)، وكورت (Kurt, 2019)، وسلام وفاروق (Salam \& Farooq, 2020). وتتفق هذه النتائج كذلك في إشارتها إلى ارتباط الاستخدام برضا المستخدم مع نتائج دراسة كل من لياو (Riaw, 2007)، ورامايه ولي (Ramayah \& lee, 2012)، وكوسوماواتي وبريبادي وأستوتي Dreheeb, Basir \& Fabil, ) (Kusumawati, Pribadi \& Astuti, 2013) 2016). كما تتفق في إشارتها إلى أن رضا المستخدم يؤثر علن المنفعة الصافية ويعدمؤشراً قوياً عليهامع نتائج دراسة كل من يوسب (Yosep, 2015)، وسلام وفاروق (Salam \& Farooq, 2020). من جانب آخر، تختلف هذه النتائج مع نتائج دراسة كل من ياكوبو وداسوكي ( Yakubu \& (Dasuki, 2018 التي أشارت إلى أن جودة النظام لا تؤثر علن رضا المستخدم واستخدام النظام. كما أنها تختلف مع نتائج دراسة أوهلياتي وعباس (Ohliati \& Abbas, 2019) التي أظهرت أن جودة النظام لا

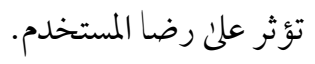
وتختلف كذلك مع نتائج دراسة سلام وفاروق (Salam \& Farooq, 2020) التي أظهرت أن جودة المعلومات لا تؤثر علن رضا المستخدم واستخدام النظام. 


\section{التوصيات}

في ضوء ما ظهر من نتائج توصي الدراسة بها يأتي:

- العناية باستقصاء جودة نظم إدارة التعلم المستخدمة في مؤسسات التعليم العالي أثناء

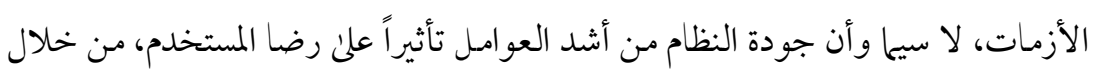

تطبيق نماذج قياس فعالية تلك النظم مثل نموذج ديلون ومكلين، ونموذج سيدون ( Seddon (model )، وغيرها. (m)

- - توجيه رسائل طلاب وطالبات الدراسات العليا في تخصص تقنيات التعليم نحو دراسة مفهوم إدارة الأزمة، وسبل استخدام تقنيات التعليم أثناء الأزمة لضمان استمرار عمليتي التعليم و التعلم.

- - توظيف نموذج الدراسة لمساعدةصانعي القرار في مؤسسات التعليم العالي في تقييم نظم إدارة التعلم المستخدمة فيها أثناء الأزمات، وتحديد العو امل الأشد تأثيراً على رضا مستخدميها.

المقترحات

$$
\text { في ضوء ما ظهر من نتائج تقترح الدراسة: }
$$

- إجراء دراسة مماثلة علن عينة أكبر تشمل الطلاب و الطالبات، وفي تخصصات أخرى مختلفة. - إجراء دراسة عن درجة رضا أعضاء هيئة التدريس عن نظام إدارة التعلم بلاكبورد واستخدامه أثناء التدريس الطارئ عن بعد.

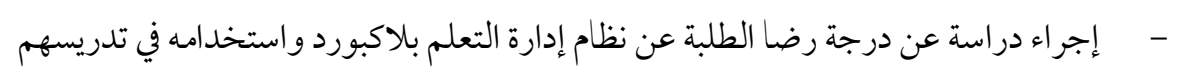
الطارئ عن بعد مقارنة بدرجة رضاهم عنه واستخدامه في تدريسهم أثناء الأوضاع المعتادة. 


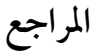

ا. الجراح، عبد المهدي علي (2011). اتجاهات طلبة الجمامعة الأردنية نحو استخدام بربجية بلاك بورد (Blackboard) في تعلمهم. دراسات العلوم التربوية، 38(4)، 1293 - 1304. r. السدحان، عبد الرحمن بن عبد العزيز (2015). اتجاهات الطلبة وأعضاء هيئة التدريس بكلية علوم الحاسب والمعلومات بجامعة الإمام محمد بن سعود الإسلامية نحو استخدام نظام إدارة التعلم الإلكتروني بلاك بورد (Blackboard) وعلاقته ببعض المتغيرات. مجلة العلوم

$$
\text { التربوية، (2)، } 225 \text { - } 278 .
$$

r. منظمة الصحة العالمية (2020). فيروس كورونا. استرجع في 5 يونيو 2020 من: .https://www.who.int/ar/health-topics/coronavirus

ع.وكالة الأنباء السعودية (2020). تعليق الدراسة في جميع مدارس ومؤسسات التعليم العام والأهلي والجامعي و الفني في المملكة اعتباراً من يوم غدٍ الاثنين وحتى إشعار آخر. استرجع في 5 يونيو 2020 من: 


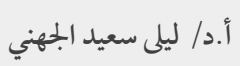

المجلد (3) العدد (4) 2020م

\section{References}

Aljarrah, Abdelmuhdi Ali (2011). University of Jordan Students' Attitudes Towards the Use of the Blackboard as a Learning Tool. Dirasat: Educational Sciences, 38(4), 1239-1304.

Al-Sadhan, Adbulrahman Abdulaziz (2015). Trends of Students and Faculty of the College of Information and Computer Sciences at Imam Muhammad Ibn Saud Islamic University towards Using ELearning Management System (Blackboard) and Its Correlation with Some Variables. Journal of Educational Sciences, (2), 225-278.

Blackboard (2020a). About us. Retrieved 8 June 2020 from: https://www.blackboard.com/about-us.

Blackboard (2020b). Blackboard Learn. Retrieved 30 May 2020 from: https://www.blackboard.com/teaching-learning/learningmanagement/blackboard-learn.

Bozkurt, A., \& Sharma, R. C. (2020). Emergency remote teaching in a time of global crisis due to CoronaVirus pandemic. Asian Journal of Distance Education, 15(1).

de Souza Meirelles, F., Filenga, D., \& Brugnolo Filho, M. (2014). Student Satisfaction Process in Virtual Learning System: Considerations Based in Information and Service Quality from Brazil's Experience. Turkish Online Journal of Distance Education, 15(3), 122-142.

DeLone, W. H., \& McLean, E. R. (1992). Information systems success: The quest for the dependent variable. Information systems research, 3(1), 60-95.

Delone, W. H., \& McLean, E. R. (2003). The DeLone and McLean model of information systems success: a ten-year update. Journal of management information systems, 19(4), 9-30.

DeLone, W. H., \& McLean, E. R. (2016). Information systems success measurement. Foundations and Trends® in Information Systems, 2(1), 1-116.

Dreheeb, A. E., Basir, N., \& Fabil, N. (2016). Impact of system quality on Users' satisfaction in continuation of the use of E-learning system. International 
Journal of e-Education, e-Business, e-Management and e-Learning, 6(1), 13.

Eom, S. B. (2014). Understanding e-learners' satisfaction with learning management systems. Bulletin of the IEEE Technical Committee on Learning Technology, 16(2), 3.

Freeze, R. D., Alshare, K. A., Lane, P. L., \& Wen, H. J. (2019). IS success model in elearning context based on students' perceptions. Journal of Information systems education, 21(2), 4.

Ghazal, S., Aldowah, H., \& Umar, I. (2017, April). Critical factors to learning management system acceptance and satisfaction in a blended learning environment. International Conference of Reliable Information and Communication Technology (pp. 688-698). Springer, Cham.

Hodges, C., Moore, S., Lockee, B., Trust, T., \& Bond, A. (2020). The difference between emergency remote teaching and online learning. Educause Review, 27. Retrieved 8 June 2020 from: https://er.educause.edu/articles/2020/3/the-difference-betweenemergency-remote-teaching-and-online-learning.

Karalis, T. (2020). Planning and evaluation during educational disruption: lessons learned from COVID-19 pandemic for treatment of emergencies in education. European Journal of Education Studies. 7(4), 124-142.

Kassim, E. S., Jailani, S. F. A. K., Hairuddin, H., \& Zamzuri, N. H. (2012). Information system acceptance and user satisfaction: The mediating role of trust. Procedia-Social and Behavioral Sciences, 57, 412-418.

Kurt, Ö. E. (2019). Examining an e-learning system through the lens of the information systems success model: Empirical evidence from Italy. Education and Information Technologies, 24(2), 1173-1184.

Kusumawati, A., Pribadi, A., \& Astuti, H. M. (2013, December). Analyzing the Influence Of Information System's Quality, User Satisfaction And Net Benefit Of E-Learning Users. Information Systems International 
Conference ISICO 2013 (pp. 155-160). Bali, Indonesia: Institut Teknologi Sepuluh Nopember.

Liaw, S. S. (2008). Investigating students' perceived satisfaction, behavioral intention, and effectiveness of e-learning: A case study of the Blackboard system. Computers \& education, 51(2), 864-873.

Noh, N. M., Mustafa, H. M. A., \& Ahmad, C. N. C. (2014). Predictive Relationship between Technology Acceptance Readiness and the Intention to Use Malaysian EduwebTV among Library and Media Teachers. ProcediaSocial and Behavioral Sciences, 116, 144-148.

Ohliati, J., \& Abbas, B. S. (2019). Measuring students satisfaction in using learning management system. International Journal of Emerging Technologies in Learning (iJET), 14(04), 180-189.

Ojo, A. I. (2017). Validation of the DeLone and McLean information systems success model. Healthcare informatics research, 23(1), 60-66.

Ramayah, T., \& Lee, J. W. C. (2012). System characteristics, satisfaction and e-learning usage: a structural equation model (SEM). Turkish Online Journal of Educational Technology-TOJET, 11(2), 196-206.

Salam, M., \& Farooq, M. S. (2020). Does sociability quality of web-based collaborative learning information system influence students' satisfaction and system usage? International Journal of Educational Technology in Higher Education, 17, 1-39.

Saudi Press Agency (2020). Suspending Study in all Public, Private and Technical schools, institutions and Universities, in the Kingdom from tomorrow, Monday, until further notice. Retrieved 8 June 2020 from: https://www.spa.gov.sa/viewstory.php?lang=ar\&newsid=2044433.

Shields, Patricia M. \& Rangarajan, Nandhini (2013). A Playbook for Research Methods: Integrating Conceptual Frameworks and Project Management. New Forums Press, Stillwater, Oklahoma 74074 U.S.A.

Tahar, N. F., Mokhtar, R., Jaafar, N. H., Zamani, N. D., Sukiman, S. A., \& Ismail, Z. (2013, December). Students' satisfaction on blended learning: The use of 
factor analysis. In 2013 IEEE Conference on e-Learning, e-Management and e-Services (pp. 51-56). IEEE.

Van Cauter, L., Verlet, D., Snoeck, M., \& Crompvoets, J. (2017). The explanatory power of the Delone \& McLean model in the public sector: A mixed method test. Information Polity, 22(1), 41-55.

Vlachopoulos, D. (2020). COVID-19: Threat or Opportunity for Online Education? Higher Learning Research Communications, 10(1), 2.

Wang, Y. S. (2003). Assessment of learner satisfaction with asynchronous electronic learning systems. Information \& Management, 41(1), 75-86.

WHO (2020a). Corona Virus. Retrieved 5 June 2020 from: https://www.who.int/ar/health-topics/coronavirus.

WHO (2020b). WHO Director-General's opening remarks at the media briefing on COVID-19 - 11 March 2020. Retrieved 8 June 2020 from: https://www.who.int/dg/speeches/detail/who-director-general-sopening-remarks-at-the-media-briefing-on-covid-19---11-march-2020.

Yakubu, M. N., \& Dasuki, S. (2018). Assessing eLearning systems success in Nigeria: An application of the DeLone and McLean information systems success model. Journal of Information Technology Education: Research, 17, 183203.

Yosep, Y. (2015). Analysis of Relationship between Three Dimensions of Quality, User Satisfaction, and E-Learning Usage of Binus Online Learning. CommIT (Communication and Information Technology) Journal, 9(2), 67-72.

Zamzuri, N. H., Shahrom, M., Kasim, E. S., Nasir, H. M., \& Mamat, M. N. (2012). The role of cognitive styles in influencing the users' satisfaction on e-learning system. Procedia-Social and Behavioral Sciences, 67, 427-435. 
